\title{
SRNL Phase II Shelf Life Studies - Series 1 - Room Temperature and High Relative Humidity
}

\author{
J. I. Mickalonis \\ J. M. Duffey
}

September 2012

Savannah River National Laboratory Savannah River Nuclear Solutions, LLC Aiken, SC 29808

Prepared for the U.S. Department of Energy under contract number DE-AC09-08SR22470. 
SRNL-STI-2012-00530

Revision 0

\section{DISCLAIMER}

This work was prepared under an agreement with and funded by the U.S. Government. Neither the U.S. Government or its employees, nor any of its contractors, subcontractors or their employees, makes any express or implied:

1. warranty or assumes any legal liability for the accuracy, completeness, or for the use or results of such use of any information, product, or process disclosed; or

2. representation that such use or results of such use would not infringe privately owned rights; or

3. endorsement or recommendation of any specifically identified commercial product, process, or service.

Any views and opinions of authors expressed in this work do not necessarily state or reflect those of the United States Government, or its contractors, or subcontractors.

\section{Printed in the United States of America}

Prepared for U.S. Department of Energy 
Keywords: 3013 plutonium storage, stress corrosion cracking, pitting

Retention: Permanent

\title{
SRNL Phase II Shelf Life Studies - Series 1 - Room Temperature and High Relative Humidity
}

\author{
J. I. Mickalonis \\ J. M. Duffey
}

September 2012

Savannah River National Laboratory Savannah River Nuclear Solutions, LLC Aiken, SC 29808

Prepared for the U.S. Department of Energy under contract number DE-AC09-08SR22470. 


\section{ACKNOWLEDGEMENTS}

The authors wish to acknowledge the following for their assistance in conducting the experimental work and metallurgical evaluations: H. M. Ajo, M. S. Blume, M. L. Crowder, J. R. Durden, F. A. Foreman, M. Y. Hightower, M. A. Lee, W. B. Matthews, D. A. Mitchell, T. R. Murphy, D. Z. Nelson, T. Reown, V. B. Timmerman, and J. E. Ziska. 


\section{EXECUTIVE SUMMARY}

The Savannah River National Laboratory (SRNL) Phase II, Series 1 shelf-life corrosion testing for the Department of Energy Standard 3013 container is presented and discussed in terms of the localized corrosion behavior of Type 304 stainless steel in contact with moist plutonium oxide and chloride salt mixtures and the potential impact to the 3013 inner container. This testing was designed to address the influence of temperature, salt composition, initial salt moisture, residual stress and type of oxide/salt contact on the relative humidity inside a 3013 container and the initiation and propagation of localized corrosion, especially stress corrosion cracking.

The integrated plan is being conducted by Los Alamos National Laboratory and SRNL. SRNL is responsible for conducting a corrosion study in small scale vessels containing plutonium oxide and chloride salts under conditions of humidity, temperature and oxide/salt compositions both within the limits of 3013 storage conditions as well as beyond the 3013 storage requirements to identify margins for minimizing the initiation of stress corrosion cracking. These worst case conditions provide data that bound the material packaged in 3013 containers. Phase I of this testing was completed in 2010.

The Phase II, Series 1 testing was performed to verify previous results from Phase I testing and extend our understanding about the initiation of stress corrosion cracking and pitting that occur in 304L under conditions of room temperature, high humidity, and a specific plutonium oxide/salt chemistry. These results will aid in bounding the safe storage conditions of plutonium oxides in 3013 containers. A substantial change in the testing was the addition of the capability to monitor relative humidity during test exposure.

The results show that under conditions of high initial moisture ( $0.5 \mathrm{wt} \%)$ and room temperature stress corrosion cracking occurred in 304L teardrop coupons in contact with the oxide/salt mixture at times as short as 85 days. In all cases, the cracking appeared to be associated with pitting or localized general corrosion. Crack initiation at other sites, such as surface imperfections or inclusions, cannot be excluded. Cracks appear in most cases to initiate through an intergranular mode and transition to a transgranular mode. 


\section{TABLE OF CONTENTS}

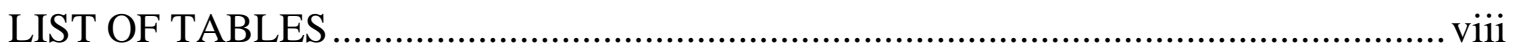

LIST OF FIGURES ……………………............................................................. vii

LIST OF ABBREVIATIONS.............................................................................

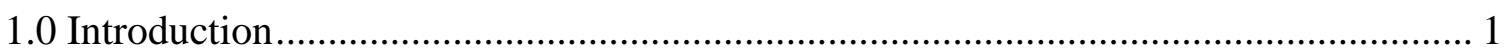

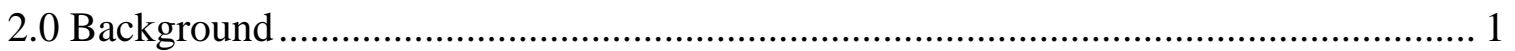

3.0 Test Configuration .......................................................................................... 3

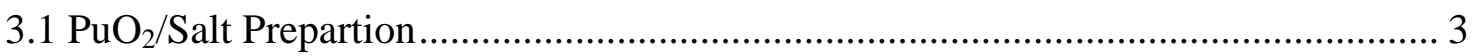

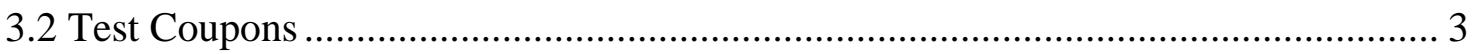

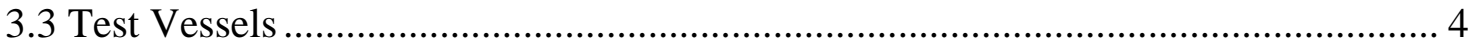

3.4 Pressure Gage, Humidity Probe, and Thermocouple Calibrations.............................. 5

3.4.1 Pressure Gage......................................................................................... 5

3.4.2 Humidity Probe ............................................................................................... 5

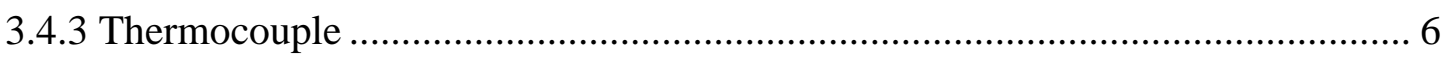

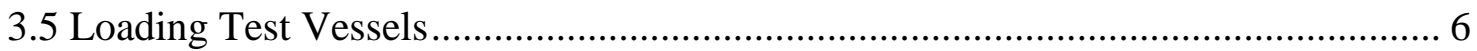

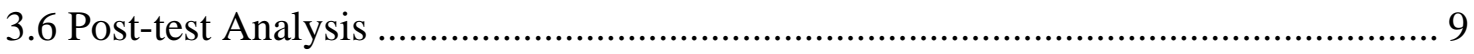

4.0 Humidity and Pressure Trends during Exposure …………..................................... 10

5.0 Corrosion of 304L Teardrops............................................................................ 12

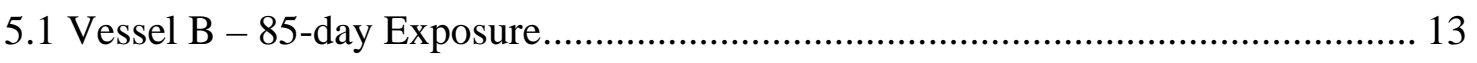

5.2 Vessel C - 175-day Exposure ………………………........................................ 18

5.3 Vessel A - 340-day Exposure ....................................................................................... 21

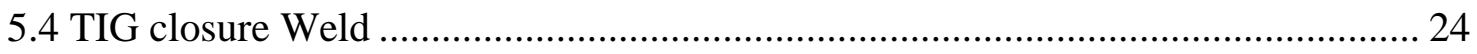

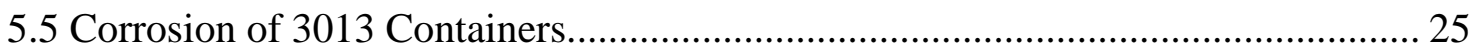

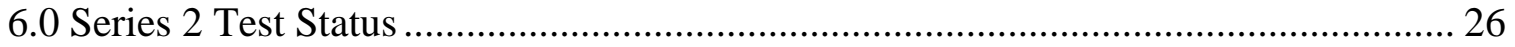

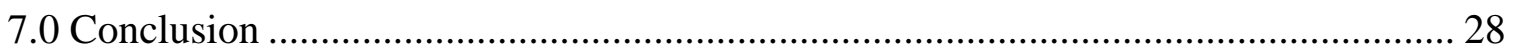

8.0 References.................................................................................................... 29 


\section{LIST OF TABLES}

Table 4-1 Headspace Gas Composition for Series 1 Test Vessels .................................. 12

Table 5-1 Teardrop Coupons Exposure Conditions and Corrosion Status ...................... 12

\section{LIST OF FIGURES}

Figure 3-1 (A) Teardrop coupon for stress corrosion cracking testing with the autogenous weld centerline indicated by the dotted line and a TIG closure weld and (B) Arrangement of oxide/salt-contact and vapor-exposed teardrop coupons in test vessel.

Figure 3-2 Comparison of small-scale corrosion test vessels: (A) Phase I testing using pressure monitoring and gas sampling capability and (B) Phase II testing using pressure sensor, humidity probe, thermocouple, and gas sampling capability

Figure 3-3 Calibration curves for humidity probes used in the Phase II, Series 1 smallscale shelf-life testing

Figure 3-4 Photograph of the glovebag, deployed inside a radiological glovebox, used to provide a humidity-controlled helium atmosphere for moisture loading oxide/salt mixture and packaging with teardrop coupons in instrumented, stainless steel test containers

Figure 3-5 Mocked up arrangement of 304L teardrop coupons and oxide/salt mixture (sand substituted in photograph) held in glass "boat" insert inside glass test vessel (glass vessel for visualization only)

Figure 3-6 Sample mass gain, purge $\mathrm{RH}$, and glovebag $\mathrm{RH}$ as a function of time during exposure of oxide/salt mixtures to humidified helium atmosphere for loading Series 1 test vessels

Figure 3-7 Mounted section of coupon TD05 from Vessel B after 85-day exposure of Series 1 test

Figure 4-1 Trends in exposure conditions for Series 1 test: (A) relative humidity and temperature and $(\mathrm{B})$ pressure

Figure 5-1 Photographs of Vessel B teardrop coupons after 85-day exposure: (A) TD04, vapor exposure, as-is condition; (B) TD05, oxide/salt contact, as-is condition; and (C) TD05, oxide/salt contact, after nitric acid cleaning

Figure 5-2 SEM micrographs of pitting on coupon TD05: (A) pitting in area outside autogenous weld (100x) and (B) pit measurement of small pit in autogenous weld (1000x)

Figure 5-3 SEM micrographs of pitting and localized corrosion on coupon TD05: (A) broad areas of corrosion near autogenous weld (arrow pointing to linear array of pits, 20x) and (B) localized breakdown of surface near pit outside of autogenous weld (2000x) 
Figure 5-4 Cross-sectional micrograph showing pitting in the heat affected zone of coupon TD05 (200x) .

Figure 5.5 Suspect cracking (shown by arrow) in coupon TD05: (A) stereo-micrograph (25X) after nitric acid cleaning and (B) SEM micrograph after alkaline cleaning $(80 \mathrm{x})$

Figure 5-6 Micrographs demonstrating the presence of cracks in coupon TD05: (A) SEM micrograph of single pit with suspect crack (as indicated by arrow) at the bottom (500x) and (B) cross-sectional micrograph of pits and cracks near the surface (200x)

Figure 5-7 Cross-sectional micrographs showing pit morphology for coupon TD05: (A) interior surface (200x) and (B) exterior surface (200x

Figure 5-8 Cross-sectional micrograph (micrograph inverted for ease of viewing) displaying areas of crack initiation and ongoing corrosion along crack wall in coupon TD05 (200x)

Figure 5-9 Photographs of Vessel C teardrop coupons (as-is condition) after 175-day exposure: (A) TD09, vapor exposure, as-is condition; (B) TD03, oxide/salt contact, as-is condition; and (C) TD03 after nitric acid cleaning .....

Figure 5-10 Stereo-micrograph of coupon TD03: (A) pitting directionality (white line indicating direction, 5x) and (B) tiny cracks extending from pits (25x)...... 19

Figure 5-11 Stereo-micrographs of largest crack observed in coupon TD03 after 175-day exposure: (A) crack with pit along its length on exterior surface of coupon (63x) and (B) crack with pit along its length on edge of coupon (63x)......... 19

Figure 5-12 SEM micrographs of crack in coupon TD03 after 175-day exposure: (A) crack bifurcating on one end (53x) and (B) crack on edge (325x)

Figure 5-13 Cracking observed in coupon TD03 after 175-day exposure: (A) crack associate with pit (200x) and (B) cracks not associated with pits (200x) ..... 20

Figure 5-14 Stereo-micrographs of coupon TD03 with pit arrays: (A at 5x and B at 63x)

Figure 5-15 Photographs of Vessel A coupons after 340-day exposure: (A and B) coupon TD30, oxide/salt contact, as-is condition; and (C and D) coupon TD25, vapor exposure, as-is condition

Figure 5-16 Stereo-micrographs of coupon TD30 after 340-day exposure (arrows indicating secondary cracks): (A) crack on exterior surface (25x) and (B) crack on edge $(63 \mathrm{x})$.

Figure 5-17 Pitting and SCC outside the autogenous weld region of teardrop coupon TD30 after 340-day exposure: (A at 75x and B at 250x, arrows indicated crack opening)

Figure 5-18 Pitting morphology of coupon TD25 after 340-day exposure and nitric acid cleaning: (A) stereo-micrograph of pitted area (25x) and (B) SEM micrograph of “pearl necklace” morphology (94x). 
Figure 5-19 Micrographs of TIG closure weld: (A) stereo-micrograph of TD03 (25x) and (B) SEM micrograph of TD25 (19x)

Figure 5-20 Pit morphologies observed in DE 3013 containers: (A) FY10 DE2 convenience can lid (750 x), (B) FY10 DE13 convenience can after cleaning (1075x), (C) FY11 DE7 convenience can after cleaning (250x), and (D)FY11 Hanford High Moisture Can after cleaning (300x)

Figure 6-1 Moisture uptake during loading of test vessels for Series 2 test .................... 26

Figure 6-2 Trends in exposure condition for Series 2 test vessels: (A) relative humidity and temperature and (B) pressure

Figure 6-3 Photographs of Vessel A coupons after 105-day exposure in Series 2 testing: (A and B) coupon TD16, oxide/salt contact, as-is condition and (C) coupon TD18, vapor exposure, as-is condition 


\section{LIST OF ABBREVIATIONS}

$\begin{array}{ll}\text { CWG } & \text { Corrosion Working Group } \\ \text { DE } & \text { Destructive Examination } \\ \text { DOE } & \text { Department of Energy } \\ \text { HAZ } & \text { heat-affected zone } \\ \text { ISP } & \text { integrated surveillance program } \\ \text { LANL } & \text { Los Alamos National Laboratory } \\ \text { MIS } & \text { Materials Identification \& Surveillance } \\ \text { MS } & \text { mass spectrometry } \\ \text { M\&TE } & \text { measuring and testing equipment } \\ \text { OD } & \text { outside diameter } \\ \text { RH } & \text { relative humidity } \\ \text { SCC } & \text { stress corrosion cracking } \\ \text { SEM } & \text { scanning electron microscope } \\ \text { SRNL } & \text { Savannah River National Laboratory } \\ \text { TD } & \text { teardrop } \\ \text { TIG } & \text { tungsten inert gas } \\ \text { TGA } & \text { thermogravimetric analysis } \\ \text { 304L } & \text { Type 304L stainless steel } \\ \text { 316L } & \text { Type 316L stainless steel }\end{array}$




\subsection{Introduction}

The shelf-life corrosion studies are designed to validate the assumptions in the Department of Energy (DOE) Standard DOE-STD-3013 as well as provide essential information to support field surveillance activities at 3013 storage sites [1]. The shelf-life testing focuses on bounding conditions, i.e. worse case scenarios, that are believed to be more severe and rapid than would occur in packaged 3013 containers. These studies are an integrated effort between Savannah River National Laboratory (SRNL) and Los Alamos National Laboratory (LANL) to resolve, in particular, the stress corrosion cracking (SCC) issue within the 3013 storage containers [2, 3]. Under the current integrated test plan, testing was designed to address the influence of temperature, salt composition, moisture, residual stress and exposure (salt contact or vapor space over the salt) on the relative humidity $(\mathrm{RH})$ inside a 3013 container and the initiation and propagation of SCC.

In Phase I of radiological tests at SRNL, SCC was found to occur in Type 304L stainless steel (304L) teardrop coupons at room temperature when exposed to a mixture of chloride salts and plutonium oxide containing approximately $0.6 \mathrm{wt} \%$ water [4]. The next phase of testing at SRNL was designed to determine a threshold RH for SCC and evaluate the dependence on configuration (direct contact with plutonium-bearing material or vapor exposure only) needed for SCC initiation and propagation. The first series of this four-part testing of Phase II of the program is a duplicate of Phase I testing but with test vessels equipped with $\mathrm{RH}$ sensors and improved control during moisture loading of the salts. This testing has now been completed and the results are presented in this report.

\subsection{Background}

The DOE 3013 standard covers the safe interim storage of plutonium-bearing materials for up to 50 years. The 3013 container consists of nested, welded containers fabricated from 304L or 316L stainless steel (316L) for the inner can and 316L for the outer can. The stabilized plutonium-bearing materials contain chloride salts and a low $(<0.5 \mathrm{wt} \%)$ water content. A long-term integrated surveillance program (ISP) was also established by the standard to verify the safe storage requirement and is overseen by the Materials Identification and Surveillance (MIS) working group. The ISP utilizes both field surveillance of packaged 3013 containers and shelf-life testing. The shelf life testing, which is coordinated by a Corrosion Working Group (CWG), is focused on determining if SCC can occur within a 3013 container for known packaging conditions.

Within the shelf-life testing, LANL and SRNL preliminary studies demonstrated that the plutonium oxide and chloride salt mixtures were corrosive to the 300-series stainless steels [5, 6]. In LANL testing, pitting corrosion occurred in small-scale 304L vessels containing up to $0.5 \mathrm{wt} \%$ water and a plutonium oxide/salt mixture after 90 days of exposure. Temperatures ranged between approximately 43 and $46{ }^{\circ} \mathrm{C}$ for the two locations within the test vessel. Pitting depths of up to $25 \mu \mathrm{m}$ and $100 \mu \mathrm{m}$ were observed on surfaces exposed to the vapor space and in contact with the oxide mixture, respectively. In SRNL tests, 304L coupons exposed at $55{ }^{\circ} \mathrm{C}$ with approximately 0.5 $\mathrm{wt} \%$ moisture also suffered pitting corrosion to a maximum depth of $30 \mu \mathrm{m}$ on surface in 
contact with a plutonium oxide/salt mixture. A 316L coupon had pitting depths of about $10 \mu \mathrm{m}$ at the same test conditions. Coupons of both 304L and 316L exposed at ambient temperature were either not corroded or had barely detectable attack.

In the Phase I testing at SRNL, small-scale test vessels were used to evaluate the effects of chloride salt composition and the attendant radiation of plutonium oxide on the corrosion of 304L and 316L [4]. SCC and pitting were found in 304L teardrop coupons in a high moisture environment ( $0.6 \mathrm{wt} \%$ water content for oxide/salt mixture) while in contact with a plutonium oxide/salt mixture that contained $0.3 \mathrm{wt} \%$ calcium chloride. The 316L coupons showed pitting but no cracking. Pitting, however, was also found on surfaces exposed only to the vapor space for both 304L and 316L coupons. Maximum pit depths after 166 days exposure were $60 \mu \mathrm{m}$ and $100 \mu \mathrm{m}$ for 316L and 304L. However, no cracking was found in 304L teardrop coupons after exposure for 496 days to a plutonium oxide/salt mixture containing $0.92 \mathrm{wt} \%$ calcium chloride and a $0.6 \mathrm{wt} \%$ water content for the oxide/salt mixture. These results indicated that the incidence of pitting and cracking on the steel surface were a function of the moisture content and salt concentration.

The CWG of the MIS working group evaluated these results and designed a new test plan to assess the variables that are important for SCC initiation and propagation within a 3013 container [3]. This test plan addresses the recommendations set forth by the MIS working group for ensuring that SCC does not occur in 3013 containers and supports the initial integrated corrosion program defined in "2005 Update to: A Comprehensive, SiteWide Program for Addressing Potential 3013 Corrosion Issues” [7, 8]. These recommendations specify that a test plan be developed and implemented that defines the conditions under which SCC occurs with respect to the parameters that were controlled during stabilization and packaging of 3013 containers. This plan addresses the following critical questions.

1. What is the $\mathrm{RH}$ inside the 3013 container, given its process/loading history?

2. What is the threshold RH that will support SCC?

3. What containers have the highest residual stress?

4. What configuration (salt contact or vapor space) is needed for SCC initiation and propagation?

The SRNL Phase II testing will provide data to support answering questions 1, 2 and 4 and will consists of a series of four experiments. Series 1 is a replicate of test conditions from the SRNL small-scale test that initiated SCC in 304L. Several modifications to that testing included the use of a relative humidity $(\mathrm{RH})$ sensor within the closed test vessel and improved control during moisture loading of the oxide/salt mixture. The Series 1 test has been completed and the results are contained in this report. Series 2 is identical to Series 1 except at a reduced humidity; this series is currently ongoing. Series 3 and 4 will be performed at elevated temperatures to simulate the slightly elevated temperatures of 3013 containers stored within 9975 packages. The initial RH conditions for these tests are currently being determined by the CWG. 


\subsection{Test Configuration}

The preparation of the test vessel and components was similar to that used during Phase I testing [4]. The details of those preparation steps and the loading of the test vessels are presented in this section.

\section{1 $\underline{\mathrm{PuO}}_{2} /$ Salt Preparation}

The $\mathrm{PuO}_{2}$ and chloride salt mixture used for this Series 1 test had a target composition of $98 \mathrm{wt} \% \mathrm{PuO}_{2}, 0.85 \mathrm{wt} \% \mathrm{NaCl}, 0.85 \mathrm{wt} \% \mathrm{KCl}$, and $0.3 \mathrm{wt} \% \mathrm{CaCl}_{2}$. This composition was selected to replicate that used when SCC was observed previously in Phase I test of the small-scale corrosion tests [4]. The chloride salts used in this testing were taken from a master batch of a chloride salt mixture previously prepared for the non-rad humidity tests [9]. The $\mathrm{PuO}_{2}$ was taken from material known as PEOF1, which was received from LANL. PEOF1 is a high purity $(87.8 \% \mathrm{Pu})$ oxide prepared by nitric acid anion exchange oxalate precipitation and calcination to $600{ }^{\circ} \mathrm{C}$ to produce $\mathrm{PuO}_{2}$ followed by additional calcination to $975^{\circ} \mathrm{C}$ for four hours [12].

For the preparation of the chloride salt mixture, most steps were performed in an argoninert glovebox, where humidity levels were generally below $500 \mathrm{ppm}$. The requisite quantity of each chloride salt was weighed for a total mixture quantity of $500 \mathrm{~g}$. The balance and calibrated weight set were compliant with M\&TE controls. The salts were mixed together and heated to $825{ }^{\circ} \mathrm{C}$ for fifteen minutes after which the salts were visually confirmed to have melted. Pre- and post-heating weight measurements of the salt mixture showed a difference of approximately $0.15 \%$, indicating minimal losses during heating. The fused salts were ground with a mortar and pestle and stored in a glass vial in the inert glovebox until needed further.

Prior to mixing the $\mathrm{PuO}_{2}$ with the salt mixture, the oxide was dried in a furnace housed in an air glovebox. The oxide was heated to over $300{ }^{\circ} \mathrm{C}$ for approximately 15 minutes then cooled to less than $150{ }^{\circ} \mathrm{C}$ prior to mixing with the salt mixture. The salt mixture was pre-weighed in the argon glovebox where it was stored and packaged in double containment (screw-lid glass jar, placed jar in plastic jar with $4 \AA$ molecular sieve) for transfer to the air glovebox. The oxide/salt mixture was prepared by combining $52.05 \mathrm{~g}$ of $\mathrm{PuO}_{2}$ with $1.1 \mathrm{~g}$ of the chloride salt mixture. The oxide/salt mixture was place in a covered crucible and heated to $825^{\circ} \mathrm{C}$ and held for 15 minutes. The oxide/salt mixture was cooled to less than $150{ }^{\circ} \mathrm{C}$ and then packaged for transfer in a double containment similar to that used for the salt mixture.

\subsection{Test Coupons}

The test coupons were fabricated from type 304L stainless steel and were teardrop shaped. The coupons were purchased from Metal Samples Inc. (Munford AL) as part of Phase I testing. The teardrop coupons are used as a screening tool to assess stress corrosion cracking susceptibility as well as pitting corrosion. A teardrop coupon, as shown in Figure 3-1 (A), is fabricated by bending a rectangular strip $(0.75$ in $\times 4$ in $\times 0.065$ in) around a 1-inch mandrel and joining the ends by tungsten inert gas (TIG) welding. The 
teardrop specimens had a transverse autogenous weld at the center of curvature in the rounded section to provide a similar weld microstructure as is present in the inner 3013 container closure weld area. When put into test, one coupon was positioned in the oxide/salt mixture and another teardrop was only in the vapor or head space as shown in Figure 3-1 (B).

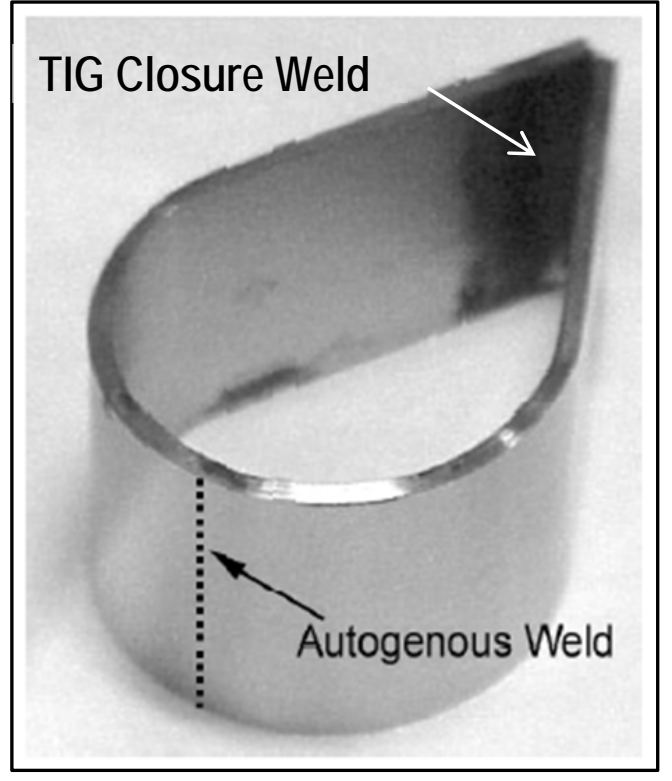

(A)

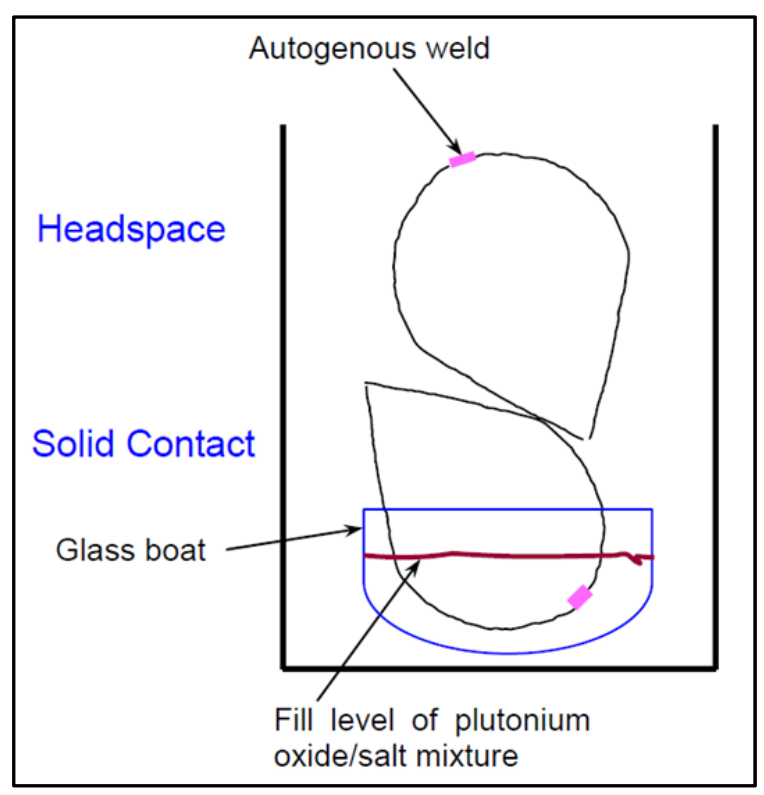

(B)

Figure 3-1 (A) Teardrop coupon for stress corrosion cracking testing with the autogenous weld centerline indicated by the dotted line and a TIG closure weld and (B) Arrangement of oxide/salt-contact and vapor-exposed teardrop coupons in test vessel [10]

\subsection{Test Vessels}

The test vessels used in the Phase II shelf-life tests are of similar design to those used for Phase I shelf-life tests [4] (Figure 3-2). For both phases of testing, a design flange with a welded bottom approximately 2 in. OD. and 2.5 in. tall was used for the bottom section. The Phase I vessel lid had a pressure sensor and valve welded directly to the flange (Figure 3-2 (A)), whereas the Phase II vessel lid flange has Swagelok fittings welded in place for a thermocouple, pressure sensor, humidity probe, and a valve for gas sampling (Figure 3-2 (B)). The vessel bottom and lid are fabricated from 304L.

The pressure sensors were supplied by General Electric (Billerica, MA) and were modified by welding a 0.125 -in. adapter. The humidity probes and thermocouples were supplied by EdgeTech (Marlborough, MA) and Omega (Stamford, CN), respectively. The dish to hold the oxide/salt mixture was made of borosilicate glass. The vessel components were helium leak tested for leak tightness [13]. The vessel bodies without the humidity probe passed the leak test and showed a rate of helium leakage of $10^{-9}$ std $\mathrm{cc} / \mathrm{s}$ at a pressure of $1 \mathrm{~atm}$. However, placement of the humidity probes generally increased the leakage and caused the leak rates to vary between $10^{-3}$ to $10^{-9} \mathrm{std} \mathrm{cc} / \mathrm{s}$. 
Several attempts were made to seal the probes with epoxy but these attempts were of limited success.

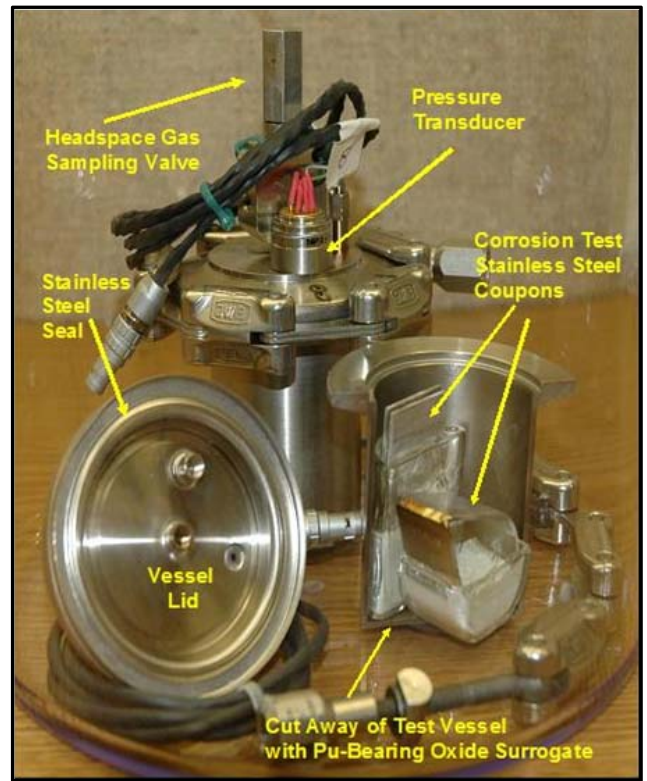

(A)

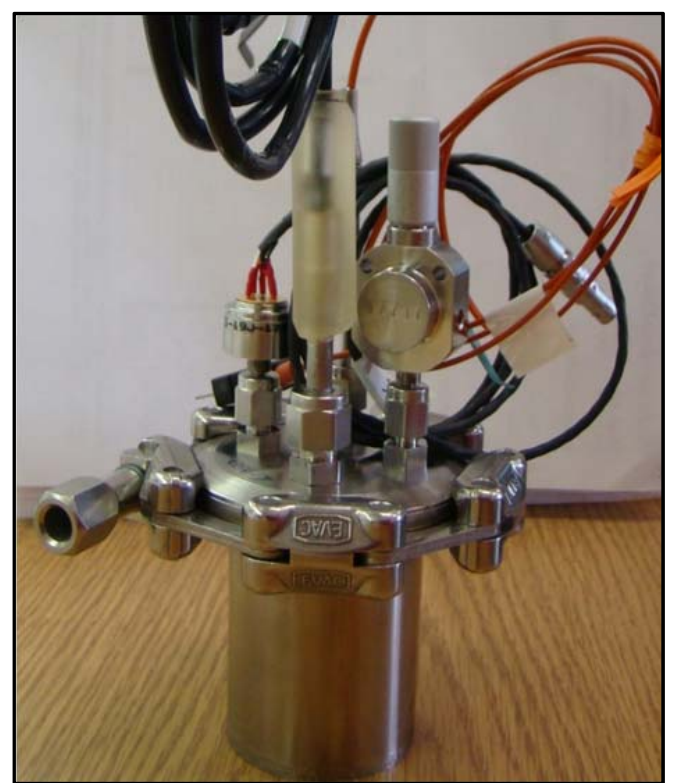

(B)

Figure 3-2 Comparison of small-scale corrosion test vessels: (A) Phase I testing using pressure monitoring and gas sampling capability and (B) Phase II testing using pressure sensor, humidity probe, thermocouple, and gas sampling capability

\subsection{Pressure Gage, Humidity Probe, and Thermocouple Calibrations}

Each pressure gage, humidity probe and thermocouple was calibrated prior to the start of testing.

\subsubsection{Pressure Gage}

The GE NovaSensor NPI-19 pressure sensors were calibrated by comparing the sensor response against a calibrated M\&TE pressure transducer. The calibration was accomplished by connecting 11 test sensors and the M\&TE sensor to a common manifold. The manifold was evacuated until at a stable pressure of $0.01 \mathrm{kPa}(0.075$ Torr) as measured by the M\&TE sensor. The voltage output of each pressure sensor was recorded. The manifold pressure was increased in increments of approximately 65 to $130 \mathrm{kPa}$ (488 to 975 Torr) to a maximum pressure of $670 \mathrm{kPa}$ (5025 Torr) while recording the voltage output of each test sensor for all the step changes. This step was repeated while decreasing the pressure back to $0.01 \mathrm{kPa}$. Calibrations were performed at 22, 23, and $25{ }^{\circ} \mathrm{C}$ because the sensor response varies with temperature. These data were used to construct calibration curves for each sensor.

\subsubsection{Humidity Probe}

The humidity probes were calibrated using a programmable chilled mirror chamber supplied by EdgeTech (Marlborough, MA) with a RH accuracy of $0.5 \%$ over the range of $5-95 \%$ (RH CAL portable humidity calibrator). Several probes were inserted into the 
chamber simultaneously and tested over a $\mathrm{RH}$ range of $5-75 \%$ at a temperature of $25{ }^{\circ} \mathrm{C}$. Probes were allowed to stabilize at each humidity level for at least 1.5 hours (usually between 2 and 3 hours). Figure 3-3 shows the calibration curves for the probes used during testing.

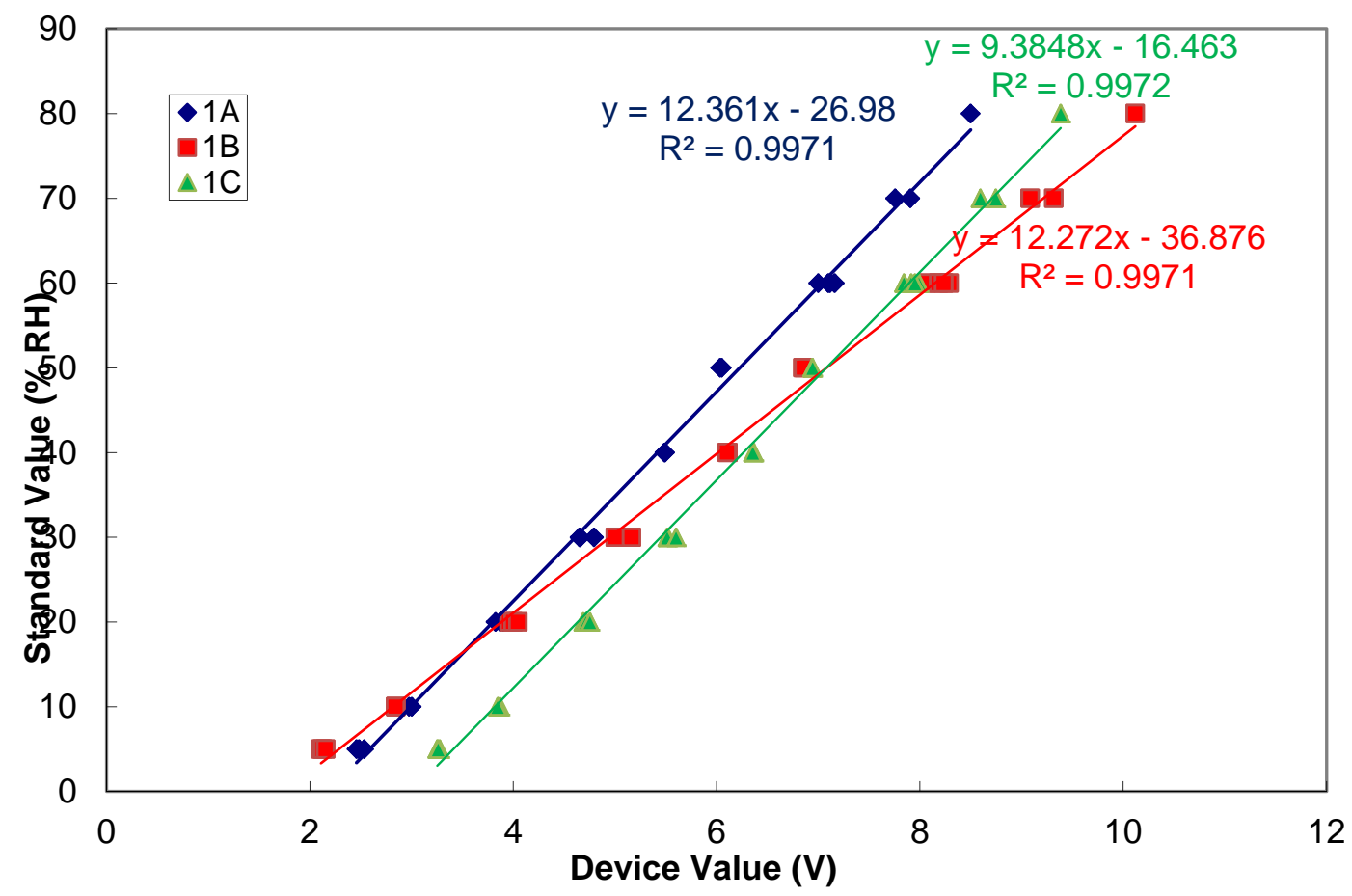

Figure 3-3 Calibration curves for humidity probes used in the Phase II, Series 1 smallscale shelf-life testing (data points are measured values and lines are best fits using a least square method)

\subsubsection{Thermocouple}

The thermocouples were checked using a Hart Scientific, Model 9107, dry-well calibrator (M\&TE) over the temperature range of $10-90{ }^{\circ} \mathrm{C}$. The thermocouples were allowed to equilibrate to a set point for approximately two hours. When the set point was either 20 or $30^{\circ} \mathrm{C}$, the thermocouple values varied from the set point by 0.3 to $0.6^{\circ} \mathrm{C}$ and at temperatures above $50{ }^{\circ} \mathrm{C}$, the variation from the set point was up to $2{ }^{\circ} \mathrm{C}$.

\subsection{Loading Test Vessels}

A helium-purged glove bag deployed inside a radiological glovebox shown in Figure 3-4 was used to provide a humidity-controlled helium atmosphere for adding water to oxide/salt mixtures and then packaging the oxide/salt mixtures and corrosion test coupons into instrumented test vessels. The humidity in the glovebag was controlled by independently adjusting the flow rates of dry and humidified helium streams. Prior to entering the glovebox, dry helium from a bank of helium cylinders was split into two streams that had independent mass flow controllers. One of the split streams of helium passed over a humidifying membrane, while the other stream was unaltered. The two 
streams were recombined into a single stream before entering the glovebox and glovebag. The humidity of the recombined stream was determined by passing a side stream over a chilled mirror dew point hygrometer. The flow rate of each stream was independently controlled to obtain the desired humidity in the helium entering the glovebag. A separate humidity probe inside the glovebag was used to monitor changes in the bag humidity. The glovebag was at ambient glove box temperature.

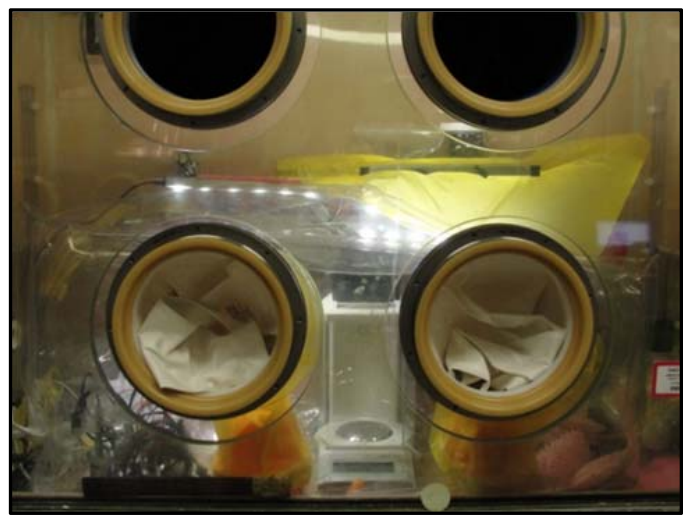

Figure 3-4 Photograph of the glovebag, deployed inside a radiological glovebox, used to provide a humidity-controlled helium atmosphere for moisture loading the oxide/salt mixture and packaging with teardrop coupons in instrumented, stainless steel test containers

The glovebag was first purged with dry helium for two hours at a flow rate of 10.0-10.5 standard liters per minute. During this time the glovebag $\mathrm{RH}$ decreased from approximately $15 \%$ to a minimum of approximately $6 \%$ at a temperature of $23 \pm 0.2{ }^{\circ} \mathrm{C}$. The analytical balance calibration was verified using a set of calibrated weights ranging from 1 to $200 \mathrm{~g}$. The jar containing the oxide/salt mixture (in air atmosphere) was then opened, closed, and weighed repeatedly until a constant weight was obtained, indicating the air was displaced with helium. Next, nominally $5 \mathrm{~g}$ of the oxide/salt mixture was weighed into a glass "boat" insert as shown in Figure 3-5.

One teardrop coupon was placed in the boat on top of the oxide/salt mixture, and a second portion of mixture (nominally $10 \mathrm{~g}$ ) was added to the boat within the closed loop of the teardrop coupon. The glass boat insert was placed into a small stainless steel pan for ease of handling. This process was repeated for each of three replicate samples.

The RH in the glovebag was gradually increased by increasing the flow rate of the humidified helium stream and decreasing the flow rate of the dry helium stream to achieve the desired humidity level in the recombined purge stream. The total flow rate was maintained relatively constant at about 10 standard liters per minute. The small stainless steel pans holding the sample sets were weighed periodically in the humidified helium atmosphere until the weight gain of each sample set corresponded to a water uptake of about $0.5 \mathrm{wt} \%$. The purge stream $\mathrm{RH}$, glovebag $\mathrm{RH}$, and mass gain of each Series 1 sample set are shown in Figure 3-6 as a function of time. 


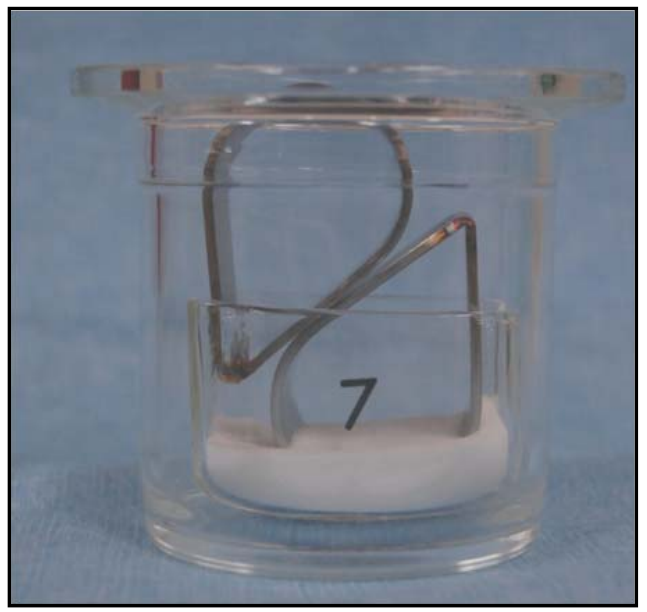

Figure 3-5 Mocked up arrangement of 304L teardrop coupons and oxide/salt mixture (sand substituted in photograph) held in glass "boat" insert inside glass container (glass container for visualization only)

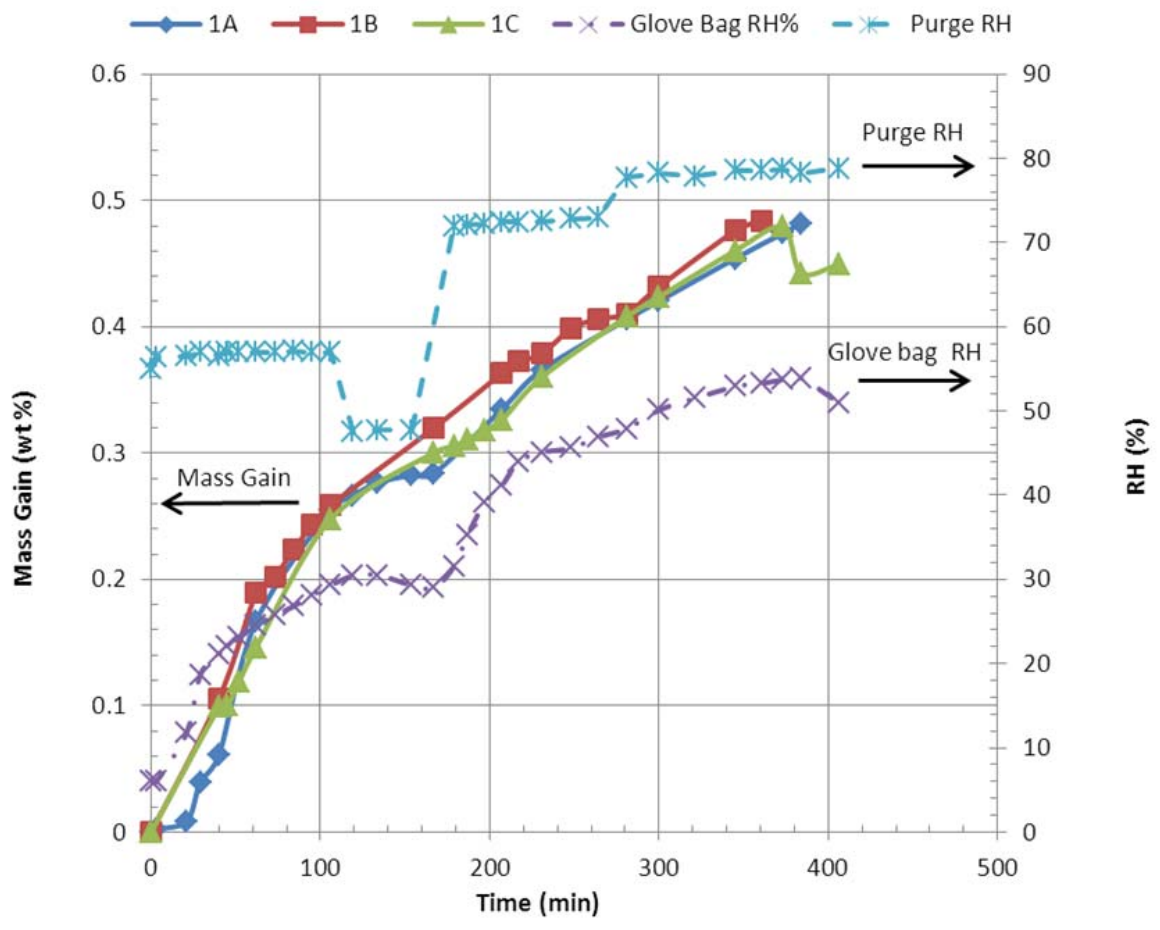

Figure 3-6 Sample mass gain, purge $\mathrm{RH}$, and glovebag $\mathrm{RH}$ as a function of time during exposure of oxide/salt mixtures to humidified helium atmosphere for loading Series 1 test vessels

The helium purge stream was initially set to a RH of about 57\%. At about $110 \mathrm{~min}$, the $\mathrm{RH}$ of the helium purge was decreased temporarily to about $47 \%$. During this time the glovebag $\mathrm{RH}$ and the rate of moisture uptake by the samples decreased more than 
anticipated. At about 167 min the RH of the helium purge stream was increased to about $72 \%$, and then gradually increased to a maximum of almost $79 \%$ before the samples reached the target moisture loading of approximately $0.5 \mathrm{wt} \%$.

As each sample set reached the targeted water loading, the glass insert containing the oxide/salt mixture and teardrop coupon was placed into a stainless steel test vessel. The second teardrop coupon was then placed on top of the first coupon as shown in Figure 3-5, and the vessel was sealed by compressing a metal gasket between upper and lower flanges held together by a chain clamp encircling and overlapping the outer edges of the two flanges. This process was repeated for each of the three sample sets. The initial fill gas of each vessel was nominally $100 \mathrm{kPa}$ of helium.

The sealed test vessels were removed from the helium glovebag, bagged out of the glovebox, and transferred to a separate air-atmosphere radiological glovebox for the test duration. The test vessels were connected to the computer data acquisition module within less than 24 hours of being sealed. The computer data acquisition system electronically monitored and recorded internal pressure, temperature, and relative humidity for each test vessel. As the vessels were connected, the humidity probe for Vessel A was found to have malfunctioned; therefore no $\mathrm{RH}$ data was obtained for the duration of the test until just prior to opening the container. However the initial RH measured for Vessels B and $\mathrm{C}$ were in good agreement with each other and with the final $\mathrm{RH}$ of the glovebag during the moisture uptake process.

\subsection{Post Test Analysis}

At the conclusion of a test, a gas sample of the head space for each vessel was pulled for analysis by gas chromatography. For Vessels B and C, a sample of the oxide/salt mixture was taken for moisture analysis by TGA/mass spectrometry (MS). Work was performed quickly since the glovebox was not humidity controlled. The teardrop coupons were photographed (35 mm) to document the as-is condition.

The coupons were then cleaned in $0.1 \mathrm{M}$ nitric acid solution to remove corrosion products. A small brush was used to dislodge any adherent corrosion product. This cleaning step was not sufficient to remove adherent oxides. Coupons were dried and then photographed (35-mm and stereomicroscope) again. Prior to examination on a scanning electron microscope (SEM) and serial metallography, coupons were cleaned by sonication in an alkaline cleaner. This cleaning removed most of the adherent oxide products.

After SEM observations, areas of interest on the teardrop coupons were identified for serial metallography. These areas were cut from the coupon and mounted in epoxy as shown in Figure 3-7 (the light colored semi-circular mark on the sample is the autogenous weld). The surfaces were prepared by progressing through a series of silicon carbide papers of decreasing grit size and then polished using diamond paste. Samples were etched using an electrolytic oxalic acid (10 wt \%) procedure. These samples were examined using a microscope of variable magnification to assess the pitting and SCC. The surface was then ground and polished again with removals ranging from 140 to 820 
$\mu \mathrm{m}$. The initial plan was to stay within some of the large pits, but removal between preparations was too significant. Pits were photographed along the section and pit depths and widths measured.

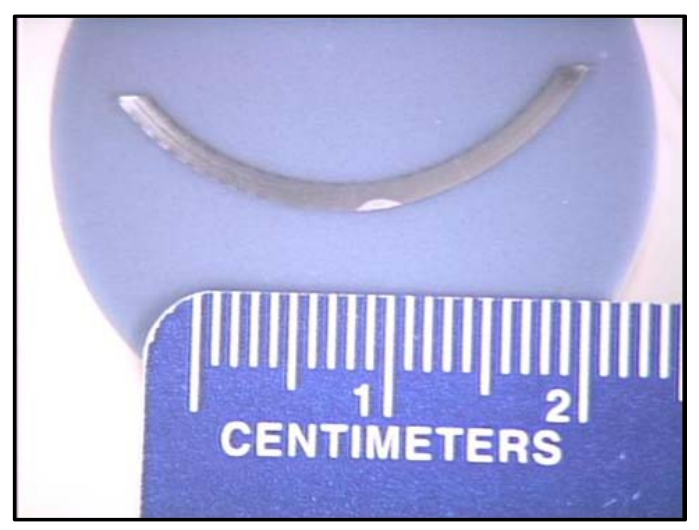

Figure 3-7 Mounted section of coupon TD05 from Vessel B after an 85-day exposure of Series 1 test

\subsection{Humidity and Pressure Trends during Exposure}

The RH, temperature and pressure trends of the three test vessels are shown in Figure 4-1. The $\mathrm{RH}$ probe in Vessel A did not generate a signal from the start of the test and troubleshooting was unsuccessful. The other vessels had fairly constant RH with Vessel $\mathrm{B}$ ranging between 53.5 to $54.7 \%$ and Vessel C in the range of 56.5 to $58 \%$. The temperature varied from approximately 19 to $24{ }^{\circ} \mathrm{C}$, increasing slightly over the sixmonth period. This increase reflected a seasonal temperature change.

Prior to opening Vessel A, the non-functioning humidity probe was replaced with a functioning probe. The switch was made after the gas sample had been pulled. The humidity was allowed to stabilize overnight. The average $\mathrm{RH}$ value was $49.5 \%$ over the next five days, which is in reasonable agreement with measured humidity for Vessels B and $\mathrm{C}$.

Moisture measurements of the oxide/salt mixture were taken after testing to verify initial moisture uptake measurements and to evaluate observed changes in the humidity and pressure trends. When the vessels were opened, samples from Vessels B and C were submitted for TGA-MS moisture analysis. Average moisture contents of $0.29 \mathrm{wt} \%$ and $0.26 \mathrm{wt} \%$ were obtained for Vessels B and C, respectively. These moisture contents were well below the 0.45 to $0.48 \mathrm{wt} \%$ determined during moisture loading. After a review of the moisture analysis data, a significant moisture loss was found to occur before the TGA heating program was initiated. These moisture analysis results are believed to be biased low, and the mass change data during moisture loading is thought to more accurately represent the initial moisture content of these samples 


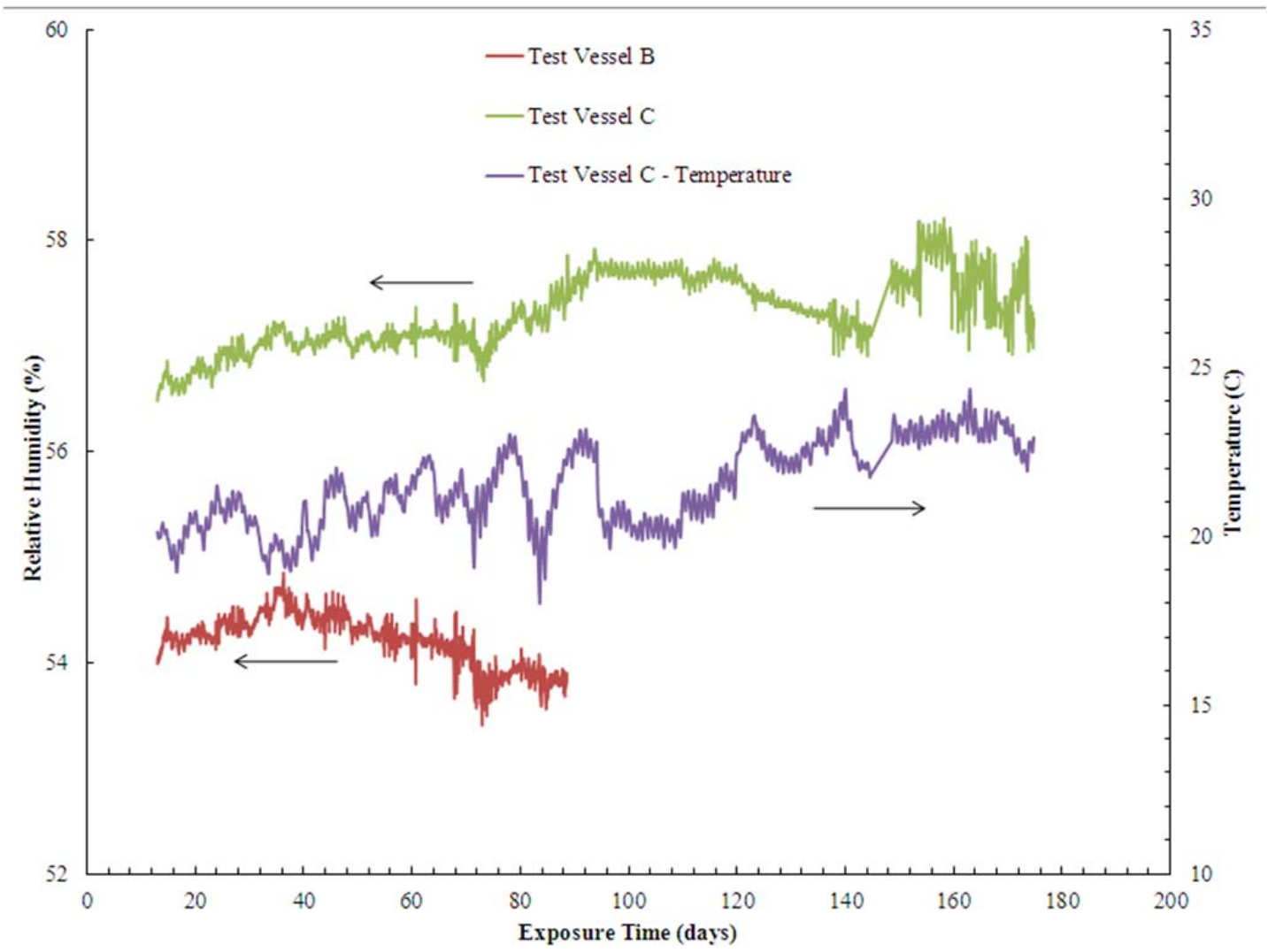

(A)

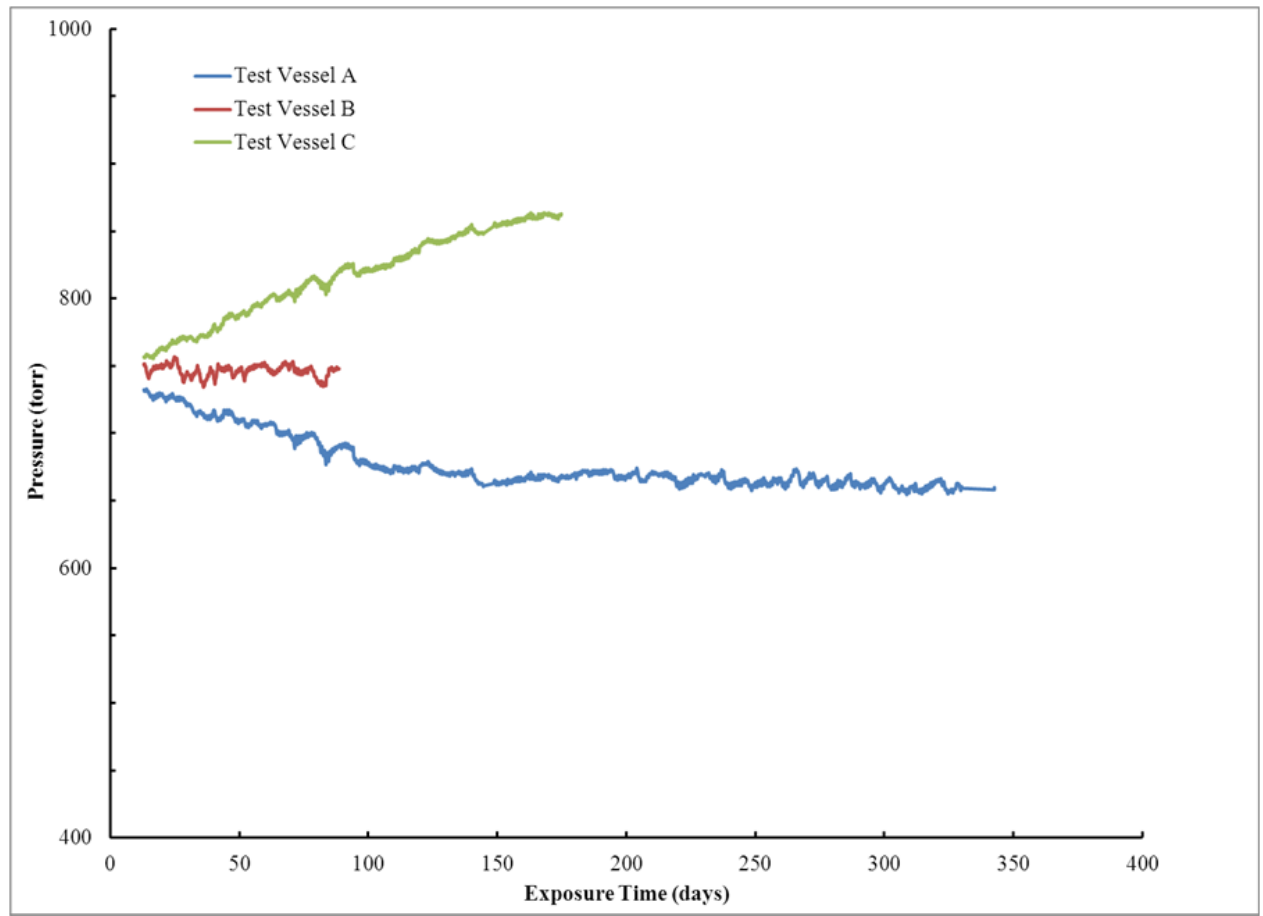

(B)

Figure 4-1 Trends in exposure conditions for Series 1 test: (A) relative humidity and temperature and (B) pressure 
The pressure trends for the test vessels differed as can be seen in Figure 4-1 (B). Vessel $\mathrm{B}$ remained at atmospheric pressure from the start of testing. This vessel did not appear to seal properly during closing. Since a leak was suspected, this vessel was opened first after 85 days. Vessel $\mathrm{C}$ showed an increasing pressure trend similar to many of the test vessels from Phase I testing. The peak pressure of approximately 860 Torr (114 kPa) occurred right before the vessel was opened at 175 days. Vessel A had a decreasing pressure until about 150 days when the pressure readings leveled at approximately 660 Torr $(88 \mathrm{kPa})$.

Prior to opening each test vessel, a gas sample from the head space was taken by expanding into a pre-evacuated $150-\mathrm{ml}$ sample vial for analysis by gas chromatography. For Vessel C, the headspace gas was diluted with helium prior to expansion to allow collection of the gas sample at greater than atmospheric pressure and minimize the potential for air in-leakage into the gas sample between sample collection and sample analysis. The results are shown in Table 4-1. Vessel B was thought to have been opened to the atmosphere and measured gas composition supports this conclusion. The results for Vessels $\mathrm{A}$ and $\mathrm{C}$ however are more difficult to rationalize in light of the pressure trends.

Table 4-1 Headspace Gas Composition (vol\%) for Series 1 Test Vessels*

\begin{tabular}{|c|c|c|c|c|c|}
\hline Vessel & $\mathbf{H e}$ & $\mathbf{H}_{\mathbf{2}}$ & $\mathbf{O}_{\mathbf{2}}$ & $\mathbf{N}_{\mathbf{2}}$ & $\mathbf{N}_{\mathbf{2}} \mathbf{O}$ \\
\hline $\mathrm{A}$ & 49.8 & 13.8 & 6.2 & 26.5 & 0.6 \\
\hline $\mathrm{B}$ & 0.6 & 0 & 19.7 & 79.8 & 0.2 \\
\hline $\mathrm{C}$ & 85.7 & 10.4 & 0 & 0.6 & 0.3 \\
\hline $\mathrm{CH}_{4}, \mathrm{CO}_{2}$, and CO & \multicolumn{7}{|c}{ not detected }
\end{tabular}

\subsection{Corrosion of 304L Teardrops}

The exposure conditions of the Series 1 testing resulted in pitting and SCC of the surfaces of the 304L teardrop coupons in contact with the oxide/salt mixture and pitting corrosion of coupon surfaces in the vapor space. Table 5-1 presents a summary of the exposure conditions and corrosion for the teardrop (TD) coupons.

Table 5-1 Teardrop Coupons Exposure Conditions and Corrosion Status

\begin{tabular}{|c|c|c|c|c|c|c|}
\hline Vessel & TD \# & $\begin{array}{l}\text { Exposure } \\
\text { Condition } \\
\end{array}$ & $\begin{array}{c}\text { Water } \\
(\%)\end{array}$ & Pressure & $\begin{array}{c}\text { Exposure } \\
\text { Time (days) }\end{array}$ & Corrosion \\
\hline \multirow{2}{*}{ A } & 30 & Oxide/Salt & \multirow{2}{*}{0.58} & \multirow{2}{*}{ Decreasing } & \multirow{2}{*}{340} & Pitting, SCC \\
\hline & 25 & Vapor & & & & Pitting \\
\hline \multirow{2}{*}{ B } & 05 & Oxide/Salt & \multirow{2}{*}{0.585} & \multirow{2}{*}{ Atmospheric } & \multirow{2}{*}{85} & Pitting, SCC \\
\hline & 04 & Vapor & & & & None \\
\hline \multirow{2}{*}{$\mathrm{C}$} & 03 & Oxide/Salt & \multirow{2}{*}{0.45} & \multirow{2}{*}{ Increasing } & \multirow{2}{*}{175} & Pitting, SCC \\
\hline & 09 & Vapor & & & & None \\
\hline
\end{tabular}


The corrosion progressed with longer exposure times at these conditions. Pitting corrosion was also observed in all TIG closure welds for the teardrop coupons, which are vapor exposed only. These results are similar to those observed during Phase I testing except crack propagation was not as extensive during this Phase II testing.

The three test vessels, B, C and A, were removed at times of 85, 175, and 340 days, respectively. The times were chosen based on the Phase I testing results, which had pitting and corrosion in 304L teardrop coupons at 166 and 335 days. A particular vessel was chosen to be opened at the designated time based on the pressure trend. Vessel B was opened first since the pressure trend for that vessel indicated that there was a leak, which was validated in subsequent gas analysis. Vessel $\mathrm{C}$ was opened second due to the increasing pressure trend.

\subsection{Vessel B - 85-day Exposure}

The teardrop coupon in contact with the oxide/salt mixture (TD05) experienced more corrosion than the coupon exposed only in the vapor space (TD04) as shown in Figure 51 (A) and (B) for the as-is condition. The TIG closure welds on both coupons, which are in the vapor space, had a buildup of corrosion products, although TD05 appeared to have less corrosion product than TD04. This difference may be associated with the orientation of the coupons' TIG welds, the vapor-exposed coupon TIG weld being closer to the oxide/salt mixture than the salt-exposed coupon TIG weld. Pitting was also observed on the interior surface of TD05 as shown in Figure 5-1 (C), which is after cleaning in the nitric acid solution.

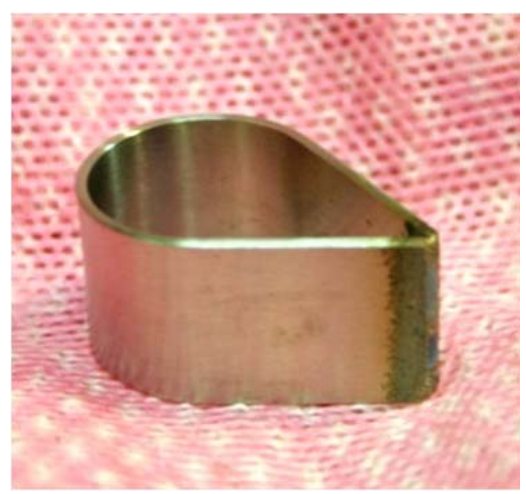

(A)

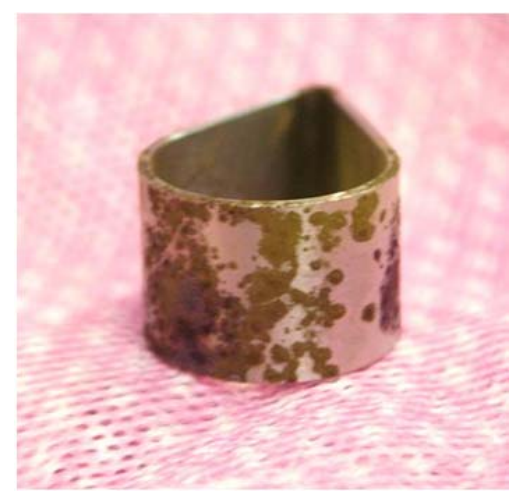

(B)

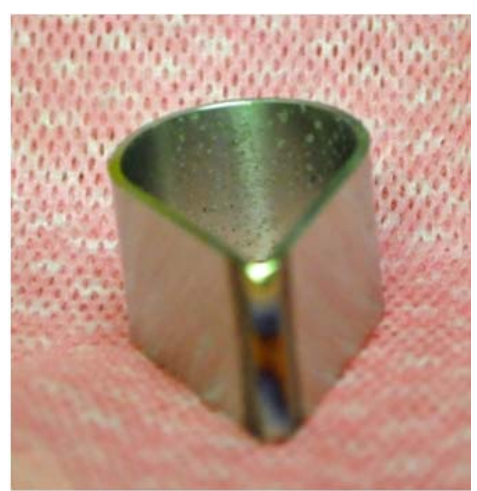

(C)

Figure 5-1 Photographs of Vessel B teardrop coupons after 85-day exposure: (A) TD04, vapor exposure, as-is condition; (B) TD05, oxide/salt contact, as-is condition; and (C) TD05, oxide/salt contact, after nitric acid cleaning

Closer examination of the surfaces of TD05 showed pits that appeared to be of two sizes as shown by the SEM micrograph in Figure 5-2 (A) for pitting outside the weld area. Elongated pits have their long axis perpendicular to the direction of the tensile stress which is parallel to the machine marks. The larger pits were on the order of $100 \mu \mathrm{m}$ diameter and smaller pits about $5 \mu \mathrm{m}$. 


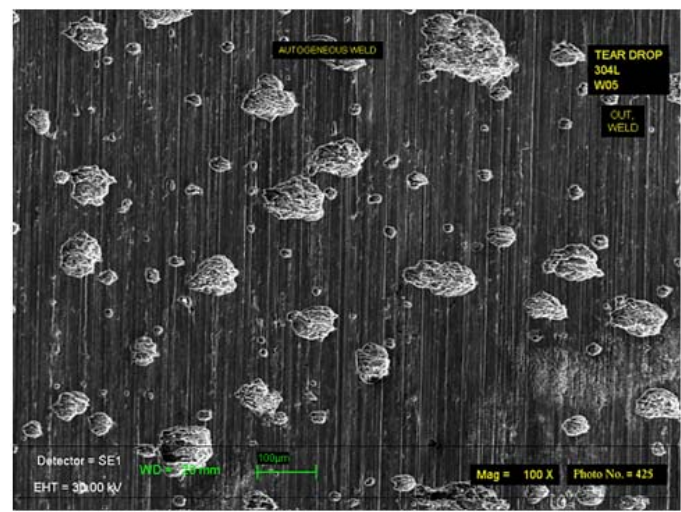

(A)

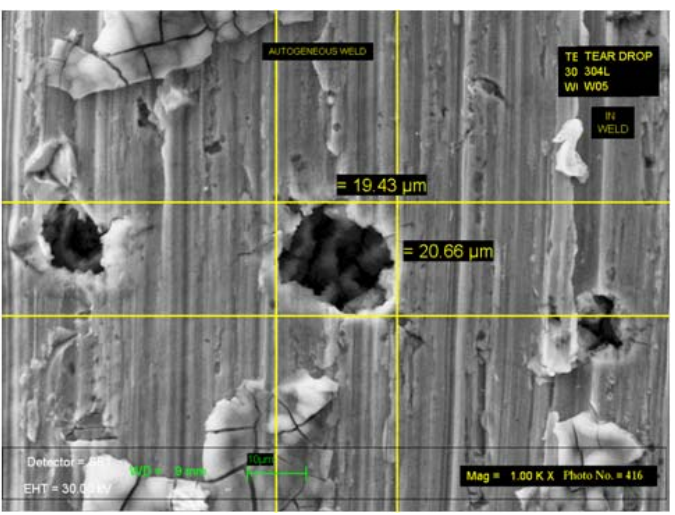

(B)

Figure 5-2 SEM micrographs of pitting on coupon TD05: (A) pitting in area outside autogenous weld (100x) and (B) pit measurement of small pit in autogeneous weld (1000x)

Using the SEM, ten pits were chosen at random both from within and outside the weld for a total of 20 pits to measure the maximum and minimum diameters and to determine if there was a size differential. These pits appeared to be single pits. Pits within the weld ranged in size from $4 \mu \mathrm{m}$ to $65 \mu \mathrm{m}$ with a ratio of the long axis to short axis of $1.06 \pm$ 0.17. Pits outside the weld ranged in size from $12 \mu \mathrm{m}$ to $83 \mu \mathrm{m}$ with an average ratio of $1.21 \pm 0.16$. Figure 5.2 (B) shows the measurement of a single pit. The small pits in and outside the weld region were similar in size. Pits of smaller size can also be seen in the micrograph.

Broad areas of localized corrosion were also observed both in and out of the weld as shown by Figure 5-3 (A). These areas had nominal diameters on the order of 300 to 500 $\mu \mathrm{m}$. These areas may result from the coalescence of small pits as seem probable from the large population of pits surrounding these areas or from a more general corrosion mechanism as appears in Figure 5-3 (B) to the right of the measured pit.

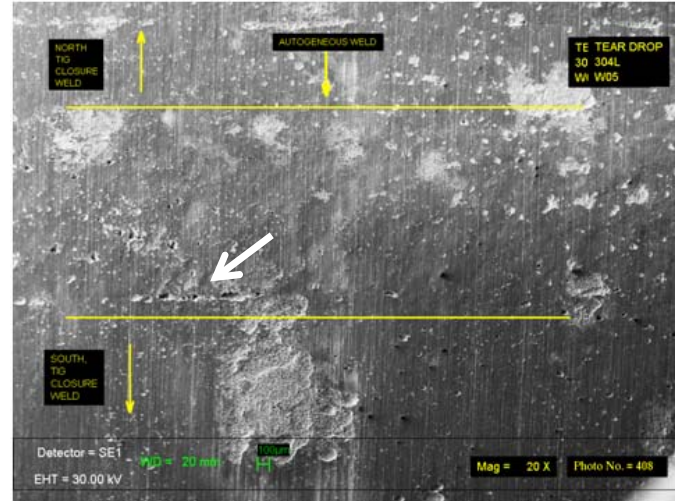

(A)

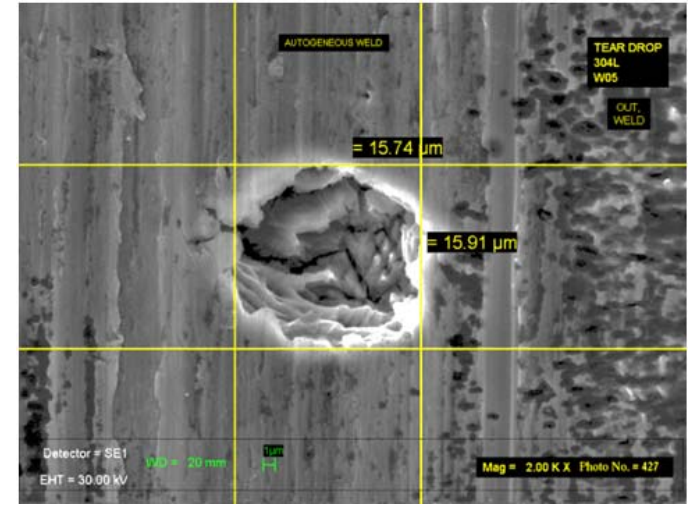

(B)

Figure 5-3 SEM micrographs of pitting and localized corrosion on coupon TD05: (A) broad areas of corrosion near autogenous weld (arrow pointing to linear array 
of pits, 20x) and (B) localized breakdown of surface near pit outside of autogenous weld (2000x)

Near the autogenous weld, pits also formed linear arrays as shown by the white arrow in Figure 5-3 (A). These arrays did not extend across the sample but in discreet segments. These pits are believed to be occurring due to preferential corrosion along the heat affected zone (HAZ). In the HAZ, both compositional and microstructural changes occur due to heat input from the welding process. These changes may lead to an increased susceptibility to corrosion. Figure 5-4 shows a cross-sectional micrograph of a pit in the HAZ of the autogenous weld in TD05

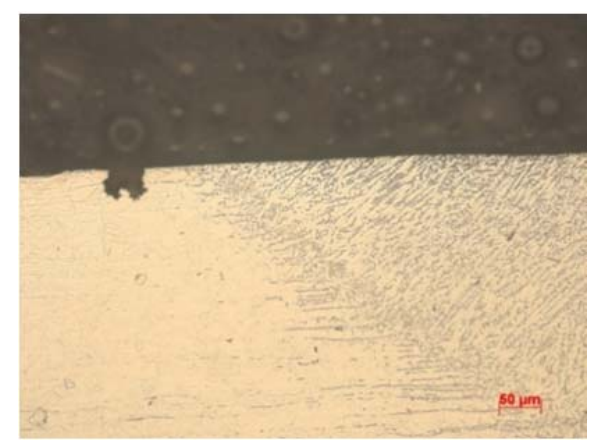

Figure 5-4 Cross-sectional micrograph showing pitting in the heat affected zone of coupon TD05 (200x)

Cracking in TD05 was suspected after examination of the coupon on the stereomicroscope as shown in Figure 5-5 (A), however, corrosion/oxidation products on the surface obscured the suspect crack area. After alkaline cleaning, an array of pits was observed on the surface (Figure 5-5 (B)). Cracking was still suspect because of the indications at the bottom of the pits as shown by the arrow in Figure 5-5 (B). Pits are known to be initiation points of cracks, but further corrosion may also be occurring at the surface as the crack advances. Further evidence for this phenomenon is given below.

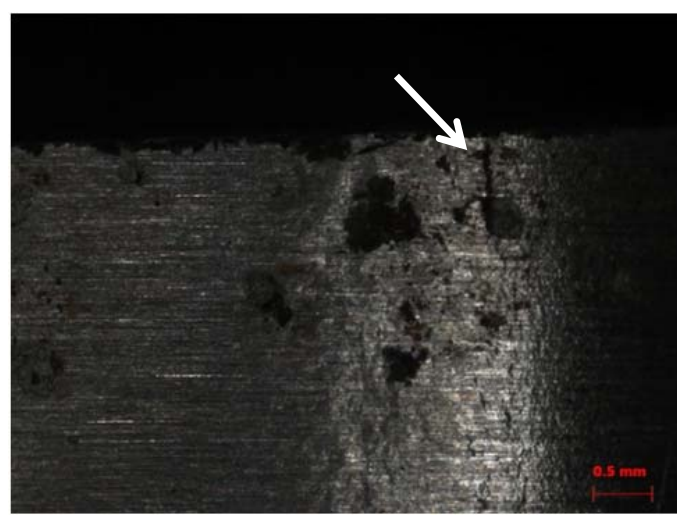

(A)

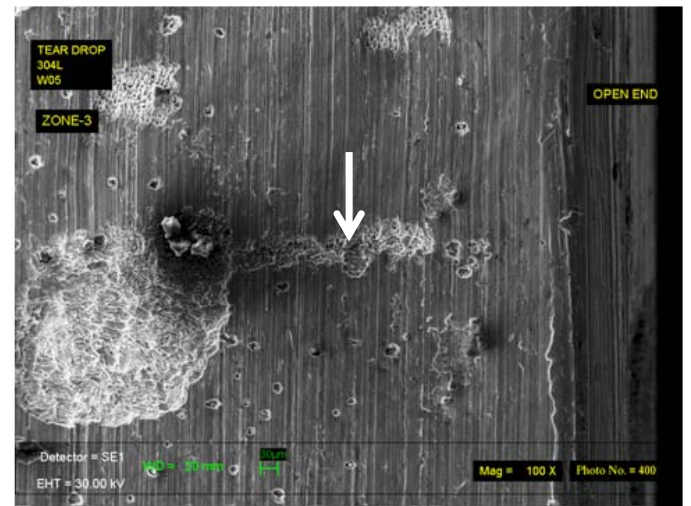

(B)

Figure 5.5 Suspect cracking (shown by arrow) in coupon TD05: (A) stereo-micrograph (25X) after nitric acid cleaning and (B) SEM micrograph after alkaline cleaning (80x) 
Suspect cracks were also observed in smaller pits as indicated by the arrow in Figure 5-6 (A) and confirmed by cross-sectional metallography of TD05 (Figure 5-6 (B)).

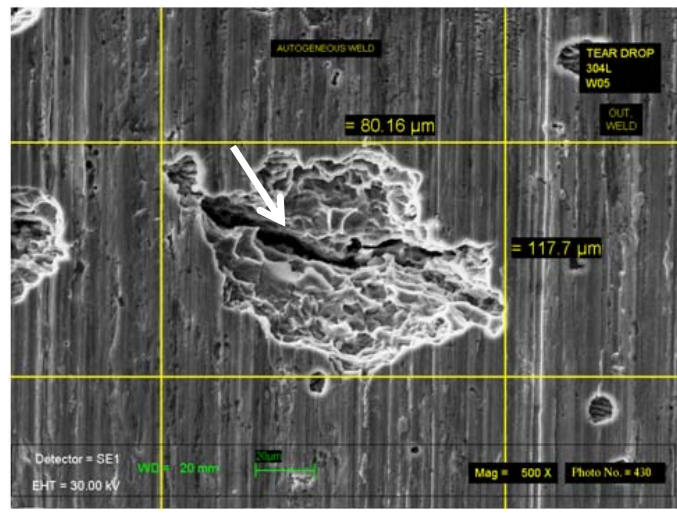

(A)

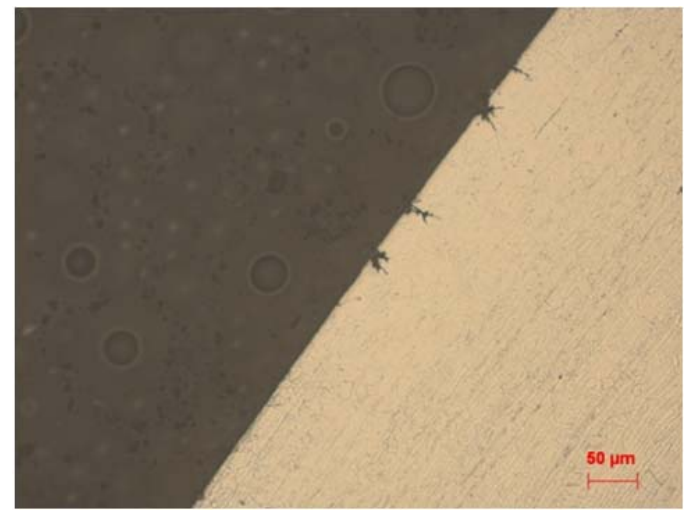

(B)

Figure 5-6 Micrographs demonstrating the presence of cracks in coupon TD05: (A) SEM micrograph of single pit with suspect crack (as indicated by arrow) at the bottom (500x), and (B) cross-sectional micrograph of pits and cracks near the surface (200x)

In the cross-sectional micrograph, two small pits $(10-20 \mu \mathrm{m})$ have cracks propagating from the bottom of the pits. Cracks (shown by white arrows in Figure 5-7 (B)) can also be observed that are associated with pits. This may indicate that crack initiation was not associated with a pit or that the pit precursor is not in this particular planar cut through TD05. The deepest cracks or penetrations fall within the range of 50-100 $\mu \mathrm{m}$. Crack or crack-like features were only noted on the exterior surface of the teardrop coupon.

The pit morphology was quite variable with some pits showing the expected hemispherical shape of a classic pit (Figure 5-7 (A)) while others had highly irregular shapes associated with preferential corrosion occurring along an advancing crack wall or along the rolling direction (Figure 5-7 (B)).

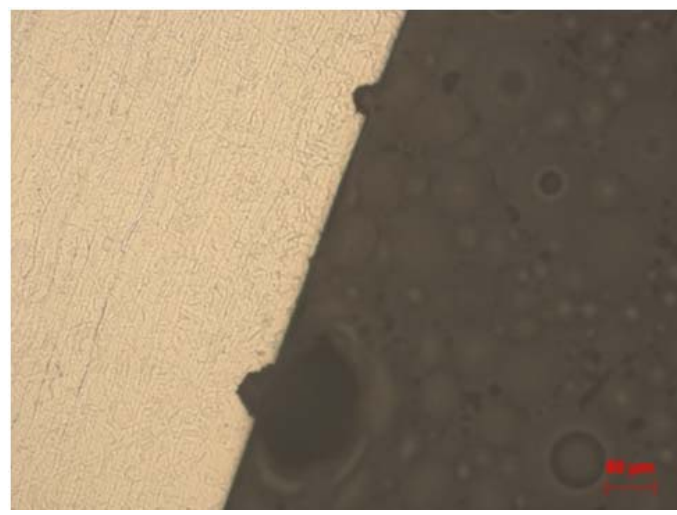

(A)

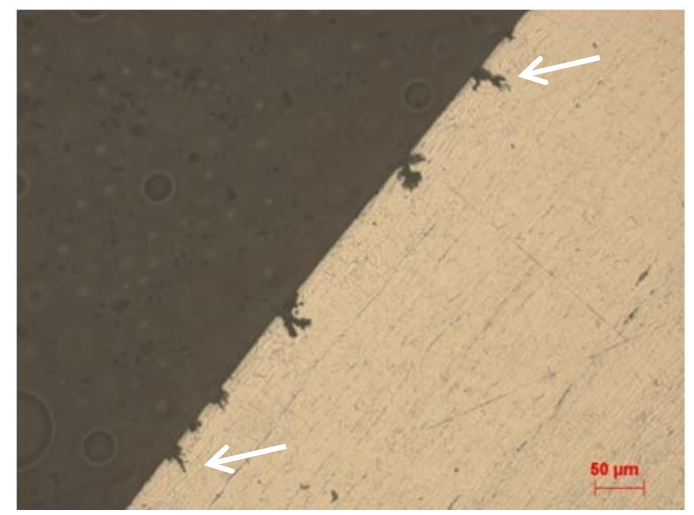

(B)

Figure 5-7 Cross-sectional micrographs showing pit morphology for coupon TD05: (A) interior surface (200x), and (B) exterior surface (200x) 
Pits on the interior surface of the teardrop coupon typically had the classic hemispherical pit morphology, while those on the exterior displayed varied morphologies. The pits on the interior surface would be in a compressive stress field where crack initiation is not expected while those on the exterior surface are in a tensile stress field where crack initiation would be expected.

Measurements were made with the micrographs from serial metallography of the pit or localized corroded area size. These measurements of either the width or depth are not necessarily the maximum measurement since these measurements are made from just one plane through the pit or corroded area. The measurements do provide a relative size. For sizes greater than $100 \mu \mathrm{m}$, widths of 116 to $550 \mu \mathrm{m}$ had depths of 19 to $74 \mu \mathrm{m}$. For size less than $100 \mu \mathrm{m}$, widths ranged from 3 to $91 \mu \mathrm{m}$ with depths of 6 to $62 \mu \mathrm{m}$. Clearly, no large pit or corroded area was found that had depths close to the measured widths of the largest pits observed in a planar view, although a number of smaller pits did. Further analysis of pit dimensions may be undertaken after additional coupons are evaluated during Phase II testing.

The corrosion morphology of TD05 provides some insight into the crack initiation and propagation within the 85-day exposure. The pit marked by the arrow in Figure 5-8 shows a widening within the crack indicating that the corrosion continues as the crack front is advancing or forming which in this case appears to be by a transgranular mode. The large pit (upper left of Figure 5-8), which is on the order of $500 \mu \mathrm{m}$ wide and $50 \mu \mathrm{m}$ deep, has not been shown to be a dominant location of crack initiation. More cracks or crack like features were observed on smaller pits.

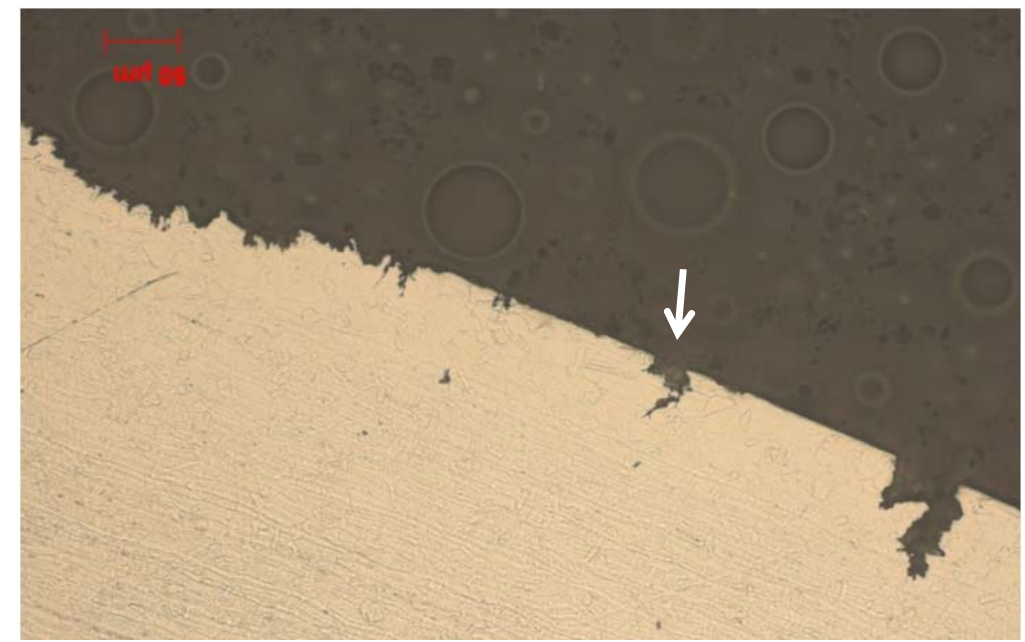

Figure 5-8 Cross-sectional micrograph (micrograph inverted for ease of viewing) displaying areas of crack initiation and ongoing corrosion along crack wall in coupon TD05 (200x) 


\subsection{Vessel C - 175-day Exposure}

The teardrop coupon in contact with the oxide/salt mixture experienced (TD03) more corrosion than the coupon exposed only in the vapor space (TD09) as shown in Figure 59 (A) and (B) for the as-is condition. The TIG closure weld on both coupons had a buildup of corrosion products, although TD03 had fewer corrosion products than TD09. This difference is probably associated with the orientation of the coupon's TIG welds, the vapor exposed coupon TIG weld being closer to the oxide/salt mixture than the saltexposed coupon TIG weld. As can be seen in Figure 5-9 (B) and (C) the pit-like features appear to have a bimodal distribution similar to coupon TD05 from Vessel B.

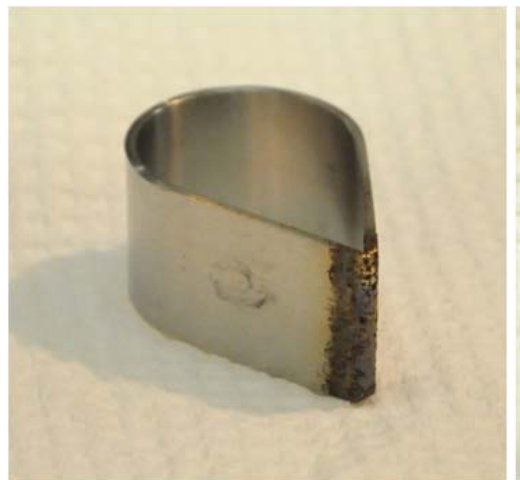

(A)

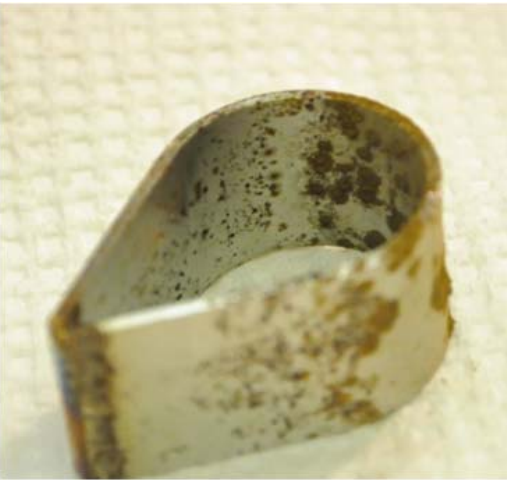

(B)

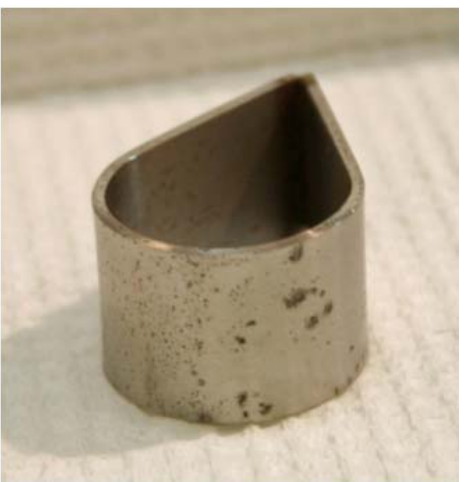

(C)

Figure 5-9 Photographs of Vessel $C$ teardrop coupons (as-is condition) after 175-day exposure: (A) TD09, vapor exposure, as-is condition; (B) TD03, oxide/salt contact, as-is condition; and (C) TD03 after nitric acid cleaning

Upon closer examination of TD03, an orientation or directionality of the pits was clearly evident as shown in Figure 5-10 (A), which shows a stereo-micrograph of the pitting near the autogenous weld (white line indicating pit orientation or directionality). Higher magnification pictures of these pits indicated that this directionality was associated in part with cracks as shown in Figure 5-10 (B). The tensile stresses are generally assumed to be perpendicular to the autogenous weld, although the direction of the crack growth may indicate otherwise.

The most significant crack was found approximately $3 \mathrm{~mm}$ from the edge of the autogenous weld, which is outside the HAZ. This crack had extended to the edge of the coupon and was longer than any of the others. The crack could be observed on the side as well, which indicated that the crack had extended part way through the coupon thickness (Figure 5-11 (A) and (B)). 


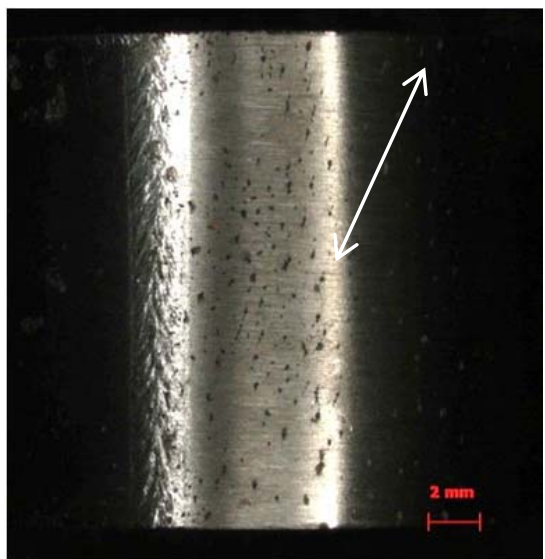

(A)

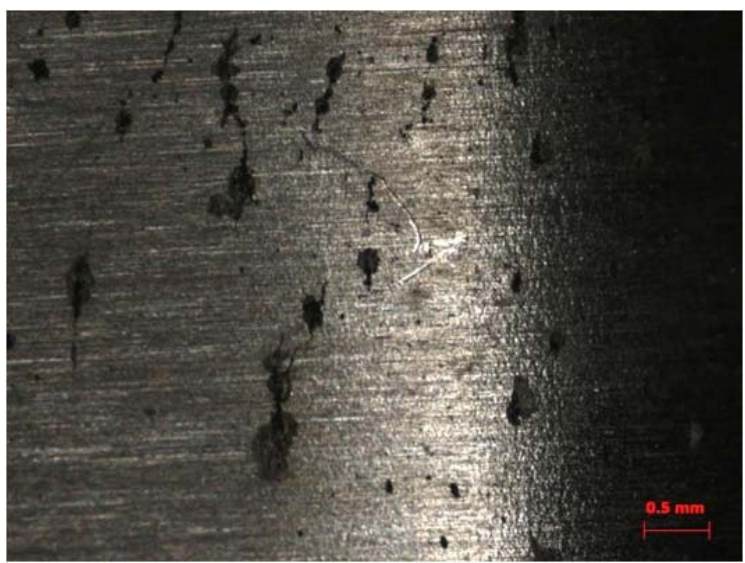

(B)

Figure 5-10 Stereo-micrograph of pitting in coupon TD03: (A) pitting directionality (white line indicating direction, $5 x$ ) and (B) tiny cracks extending from pits (25x)

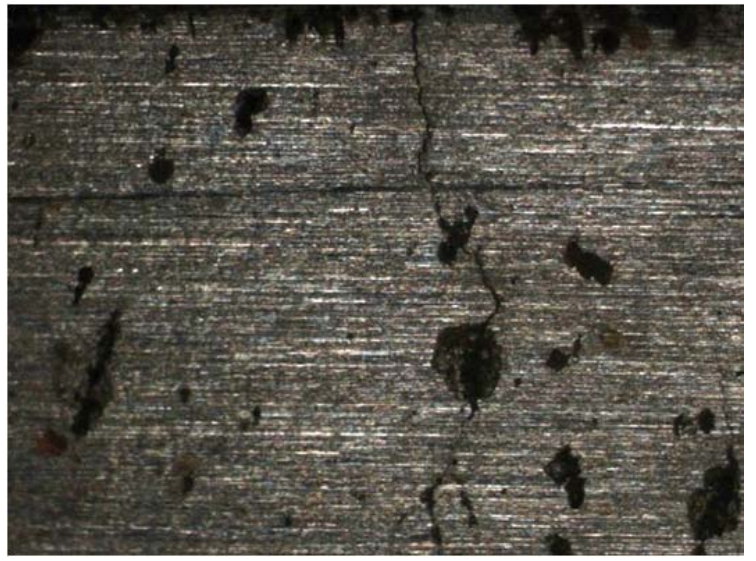

(A)

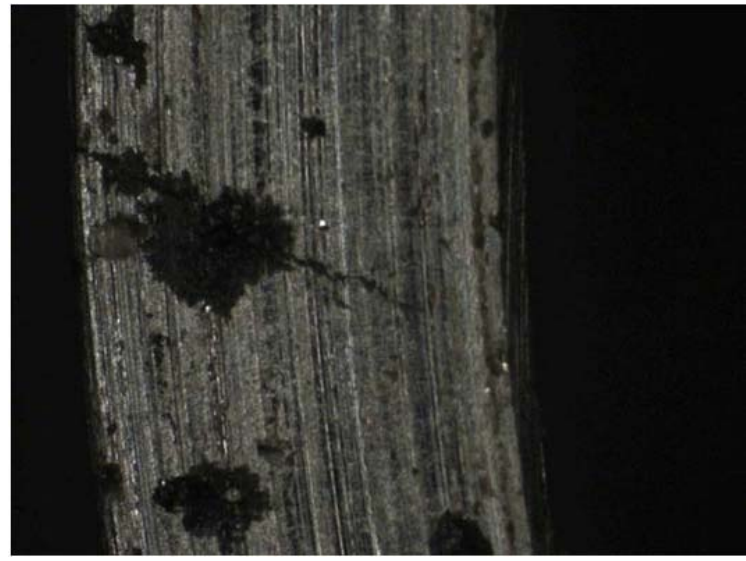

(B)

Figure 5-11 Stereo-micrographs of largest crack observed in coupon TD03 after 175-day exposure: (A) crack with pit along its length on exterior surface of coupon (63x) and (B) crack with pit along its length on edge of coupon (63x)

The cracks observed under the stereomicroscope were confirmed with the SEM after further cleaning with the alkaline cleaner to remove all the oxide products. The largest crack shown in Figure 5-11 (A) is shown again in Figure 5-12 (A). The two micrographs are approximately the same magnification. Note in Figure 5-12 (A) that the crack has branched towards the left of the pit and extends to the edge on the right side of the pit, indicating that this crack may have initiated at the pit. Note in the lower left of the micrograph the crack associated with another pit; again similar to that shown in Figure 5$11(\mathrm{~A})$. 


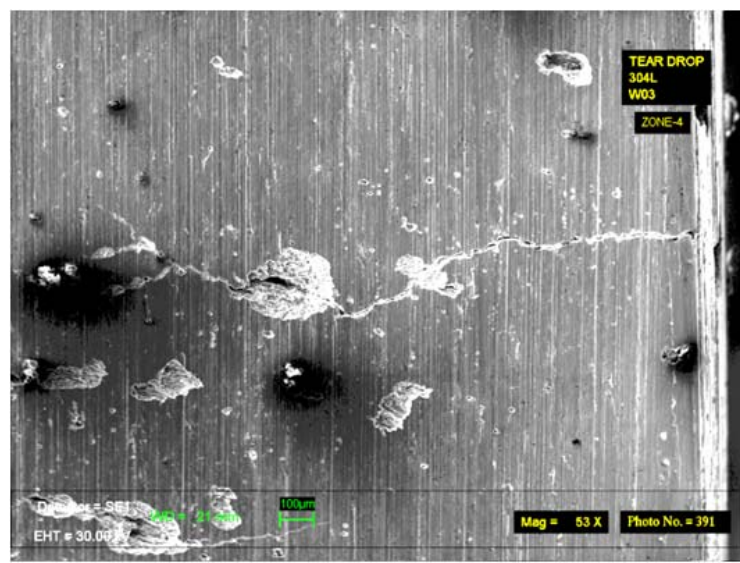

(A)

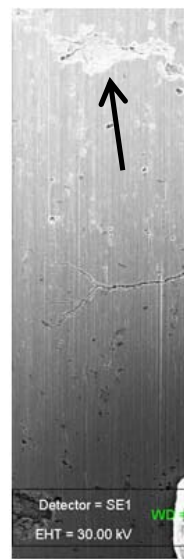
KV

Figure 5-12 SEM micrographs of crack in coupon TD03 after 175-day exposure: (A) crack bifurcating on one end (53x), and (B) crack branching on both sides of a pit (75x)

Additional cracks were observed with other pits as well as shown in Figure 5-12 (B). This crack had branched on both sides of the pit as well as several times within the corroded area. The appearance of this crack suggests that corrosion of the crack opening continues until a critical stress occurs that crack extension moves the crack front ahead of the corrosion. In this micrograph a smaller crack as indicated by the arrow corrosion associated along its entire surface opening.

After the 175-day exposure the cracks had clearly progressed well beyond the initiation site unlike after the 85-day exposure. The serial metallography clearly showed well developed cracks with extensive branching as shown in Figure 5-13 (A), a classic crack emanating from a pit. Cracks were also observed not associated with pits (Figure 5-13 (B)). From these micrographs, cracks appear to advance either via the grain boundary, through the grain, or along the rolling direction. Corrosion of the crack side wall also seems to occur as noted by the widening of the crack at locations distant from the initial crack.

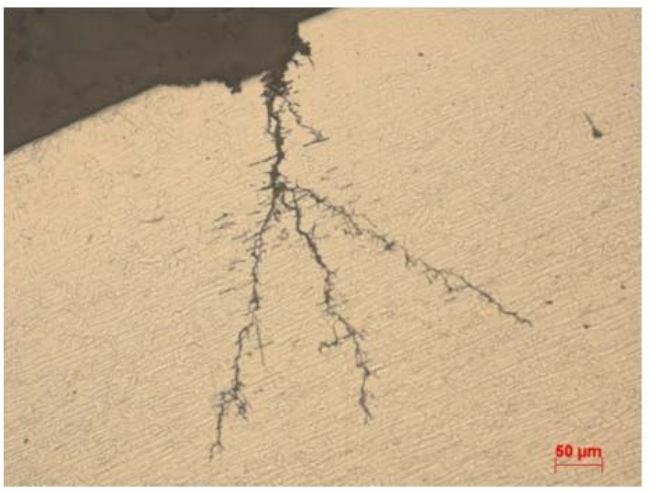

(A)

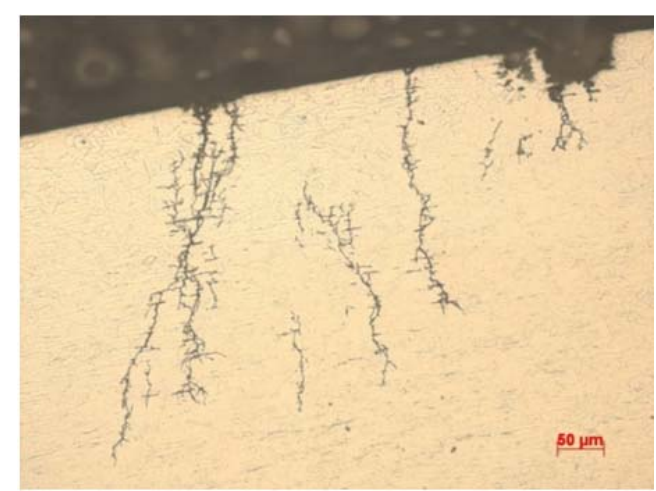

(B)

Figure 5-13 Cracking observed in coupon TD03 after 175-day exposure: (A) crack associate with pit (200x) and (B) cracks not associated with pits (200x) 
An unusual feature noted for TD03 and in the TIG weld of most coupons was a linear grouping of small pit-like features. Coupon TD03 has this on one part of the coupon facing down towards the oxide/salt mixture but not in it. The stereo-micrographs of Figure 5-14 show these arrays of pit-like features, which had a 'pearl necklace' appearance. The higher magnification micrograph gives a clearer indication of the presence of pits. These arrays were either straight or quite curvaceous.

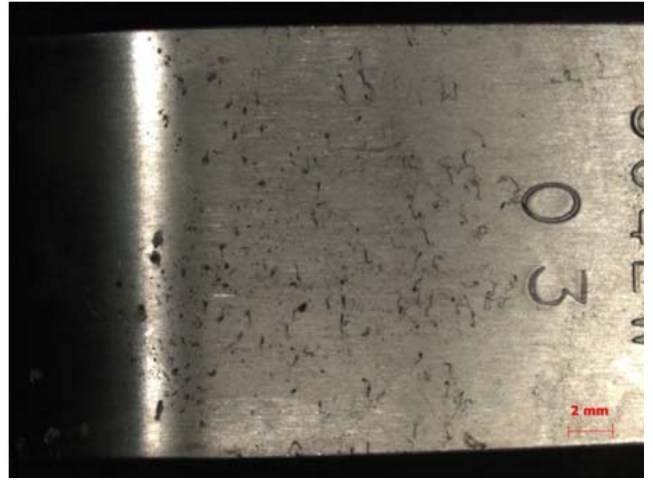

(A)

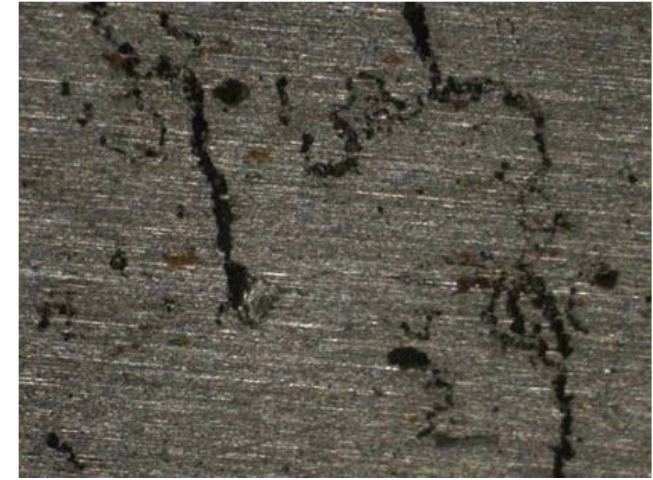

(B)

Figure 5-14 Stereo-micrographs of coupon TD03 with pit arrays (A at 5x and B at 63x)

Similar to Vessel B, ten pits were chosen at random both from within and outside the weld for a total of 20 pits to measure the maximum and minimum diameters using the SEM. These pits appeared to be single pits. Pits within the weld ranged in size from 15 $\mu \mathrm{m}$ to $59 \mu \mathrm{m}$ with a ratio of $1.16 \pm 0.2$. Pits outside the weld ranged in size from $11 \mu \mathrm{m}$ to $83 \mu \mathrm{m}$ with an average ratio of $1.31 \pm 0.08$. These measurements were similar in size to those measured in Vessel C. The small pits in and outside the weld region were similar in size.

Measurements were made with the micrographs from serial metallography of the pit or localized corroded area size. These measurements of either the width or depth are not necessarily the maximum measurement since these measurements are made from just one plane through the pit or corroded area. The measurements do provide a relative size. For sizes greater than $100 \mu \mathrm{m}$, widths of 120 to $176 \mu \mathrm{m}$ had depths of 13 to $64 \mu \mathrm{m}$. For size less than $100 \mu \mathrm{m}$, widths ranged from 8 to $98 \mu \mathrm{m}$ with depths of 3 to $50 \mu \mathrm{m}$. Clearly, no large pit or corroded area was found that had depths close to the measured widths, although a number of smaller pits did. These measurements are similar to those for TD05 after an 85-day exposure.

\subsection{Vessel A - 340-day Exposure}

The teardrop coupon in contact with the oxide/salt mixture experienced (TD30) more corrosion than the coupon exposed only in the vapor space (TD25) as shown in Figure 515 (A - D) for the as-is condition. TD30 had a spotty but heavy black and rust corrosion product layer, indicating a presence of both a hydrous ferrous oxide and a hydrated magnetite. With short duration exposures, coupons principally had a hydrous ferrous oxide as indicated by color. TD30 had corrosion products covering much more of the exposed surface area than salt-exposed coupons of short exposure times. 
The TIG closure weld on both coupons had a buildup of corrosion products. The degree of corrosion appeared similar for the two exposure conditions unlike shorter duration exposure times where the vapor-exposed coupon TIG weld appeared to have more corrosion products.

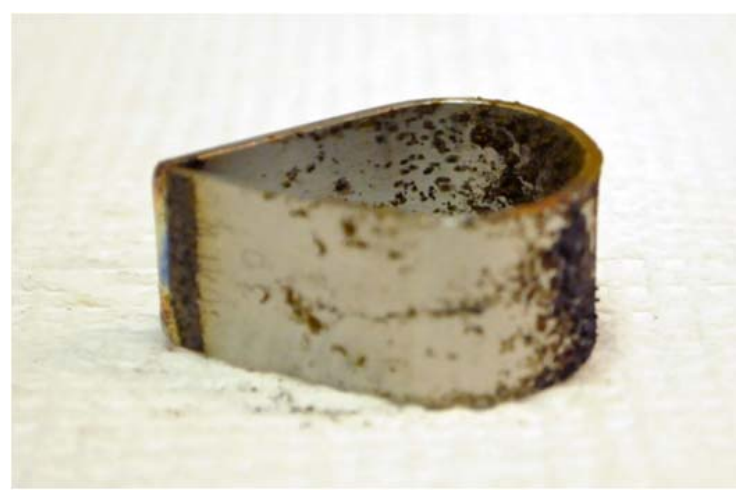

(A)

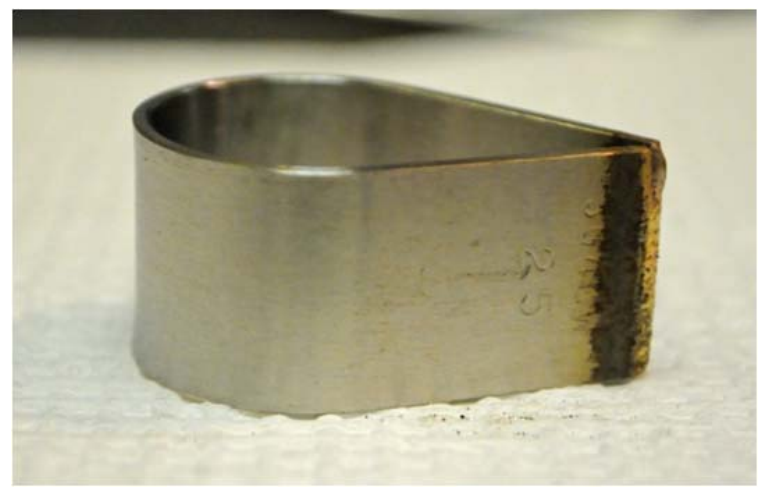

(C)

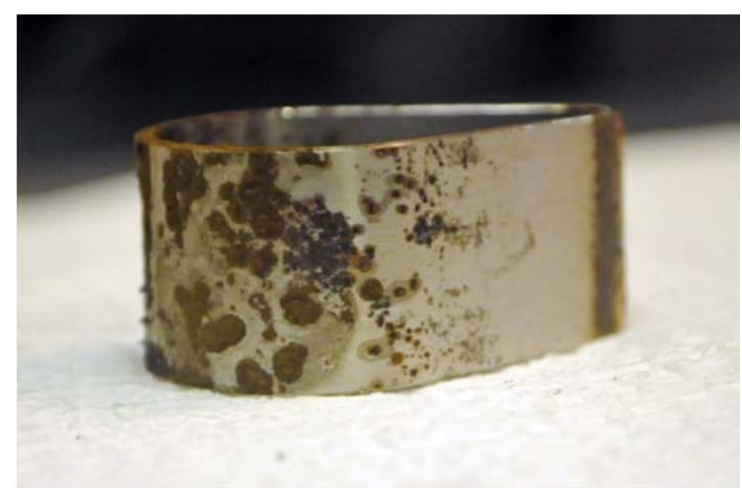

(B)

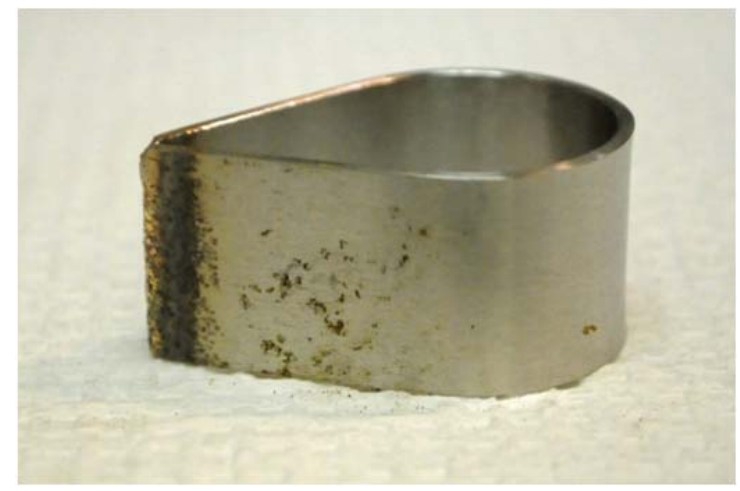

(D)

Figure 5-15 Photographs of Vessel A coupons after 340-day exposure: (A and B) coupon TD30, oxid/salt contact, as-is condition; and (C and D) coupon TD25, vapor exposure, as-is condition

For TD30 a significant near-through wall crack was observed along and through the weld unlike the coupons from shorter exposures. This crack did not grow across the entire width of the coupon. Figure 5-16 (A) and (B) shows the crack on the exterior surface and edge of TD30. Similar to other cracks observed on TD03 from Vessel C, the crack showed extensive branching. An additional crack in the weld was also present as indicated by the white arrow in Figure 5-16 (A). 


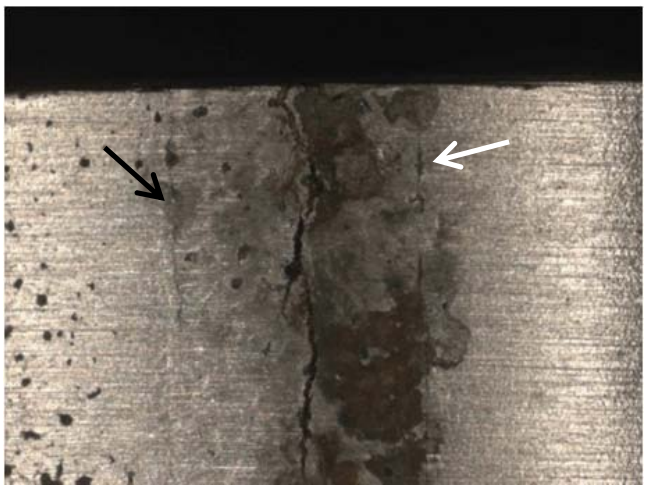

(A)

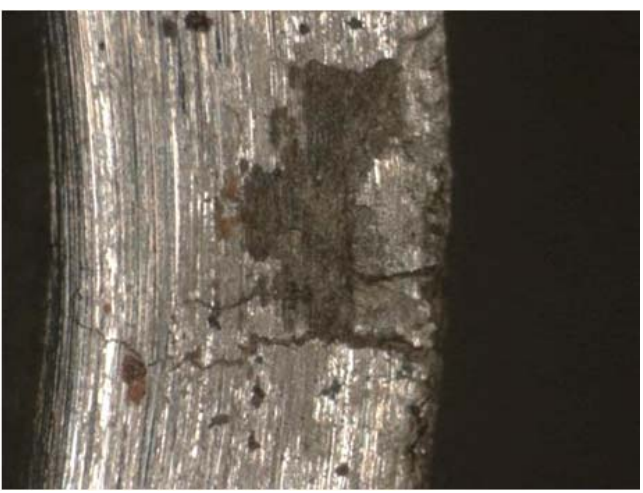

(B)

Figure 5-16 Stereo-micrographs of coupon TD30 after 340-day exposure (arrows indicating secondary cracks): (A) crack on exterior surface (25x) and (B) crack on edge (63x)

Additional cracking was also observed on the coupon outside the autogenous weld. In Figure 5-16 (A), the black arrow show a fine crack associated with a pit. Cracks were also observed on the bottom of pits outside the weld area similar to those observed on both coupons TD05 and TD03 from the 85-day and 175-day exposure. Some of these pits were in the "pearl necklace" morphology as shown in Figure 5-17 (A). This morphology appears to be more associated with pitting in vapor-exposed surfaces. Figure 5-17 (B) shows a higher magnification SEM micrograph with the crack opening apparent in the bottom of the pit.

The "pearl necklace" corrosion morphology was also observed for the coupon exposed only in the vapor space. Figure 5-18 shows both the stereo-micrograph of the pitted area as well as a higher magnification SEM micrograph of pitting similar to that shown in Figure 5-17 (A). As will be discussed below, pitting in the TIG weld shows a similar pitting morphology. All TIG welds are vapor exposed only.

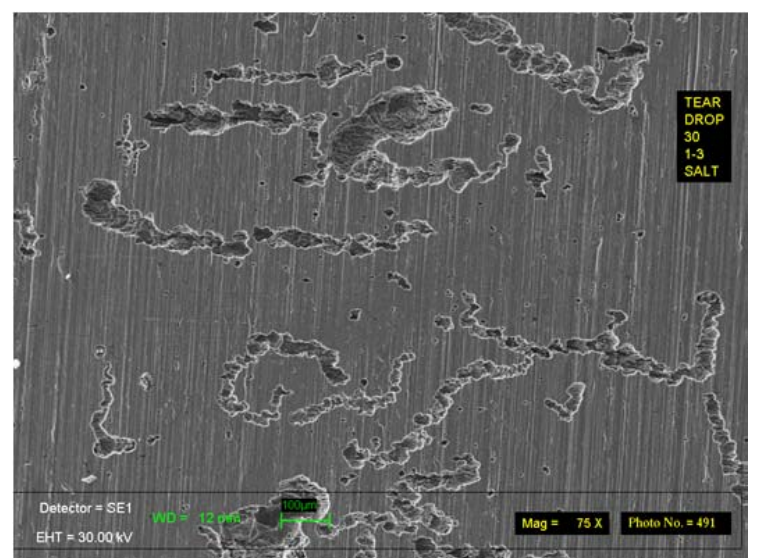

(A)

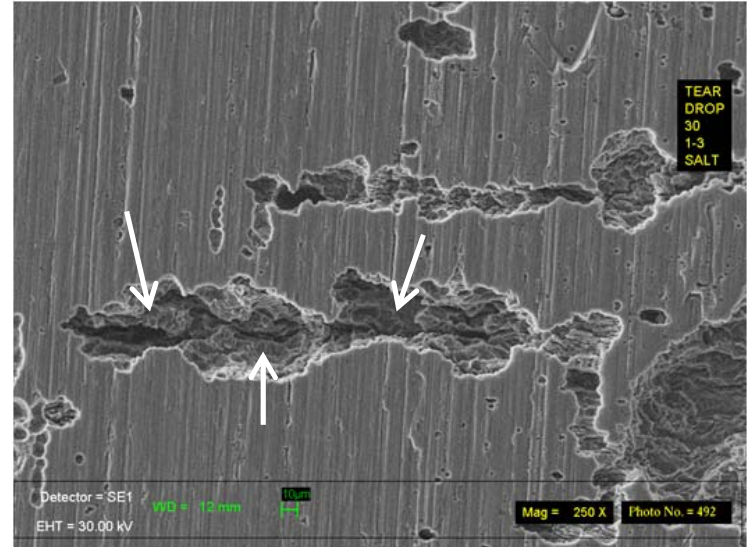

(B)

Figure 5-17 Pitting and SCC outside the autogenous weld region of teardrop coupon TD30 after 340-day exposure (A at 75x and B at 250x, arrows indicate crack opening) 


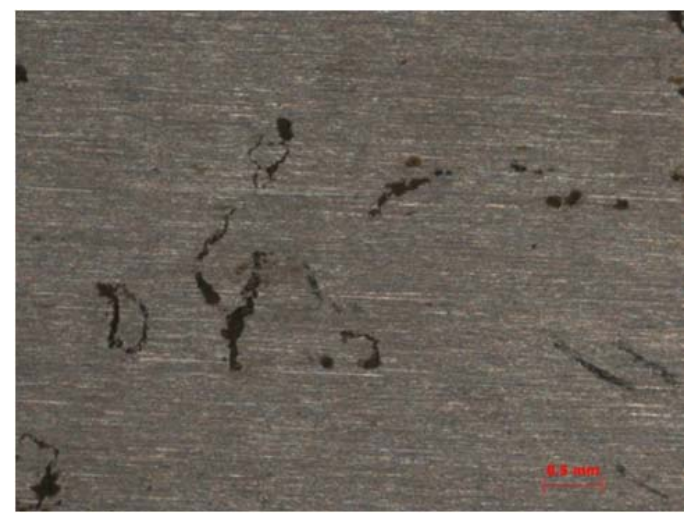

(A)

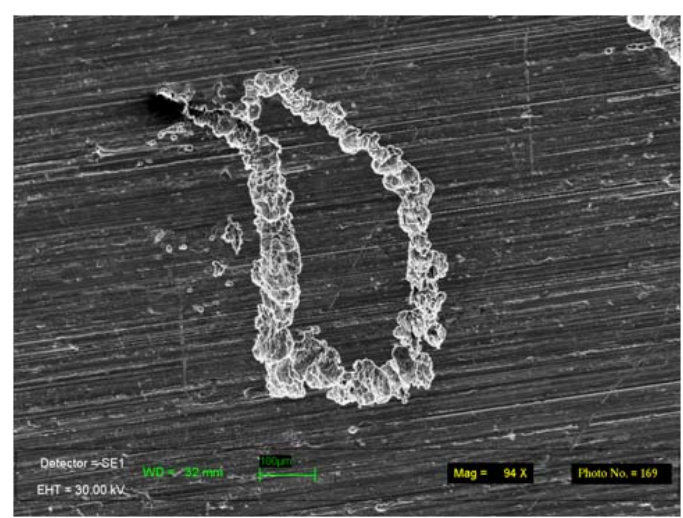

(B)

Figure 5-18 Pitting morphology of coupon TD25 after 340-day exposure and nitric acid cleaning: (A) stereo-micrograph of pitted area (25x) and (B) SEM micrograph of "pearl necklace" morphology (94x)

\subsection{TIG closure Weld}

The TIG closure weld on all the teardrop coupons in Series 1 testing had pitting or the presence of pit-like features. As can be seen in Figures 5-1, 5-9, and 5-15, the TIG weld had rust/black colored corrosion products over the surface. Similar to pitting in other vapor-exposed surfaces the pitting had a "pearl necklace" morphology as shown in Figure 5-19 (A) and (B) for TD03 and TD25, respectively. The width of these strings of pits appeared to be fairly uniform. The genesis of this type of morphology is currently unknown. Since in most cases minimal corrosion was observed on the planar vaporexposed surfaces of the teardrop coupons, the TIG closure weld, which always experienced corrosion, was more susceptible to corrosion. The TIG weld also has oxide tint on the surface that is a residual from the weld process, which tend to be more susceptible to corrosion. These results underline the concern for closure weld as being the more susceptible location for corrosion failure on the 3013 inner can.

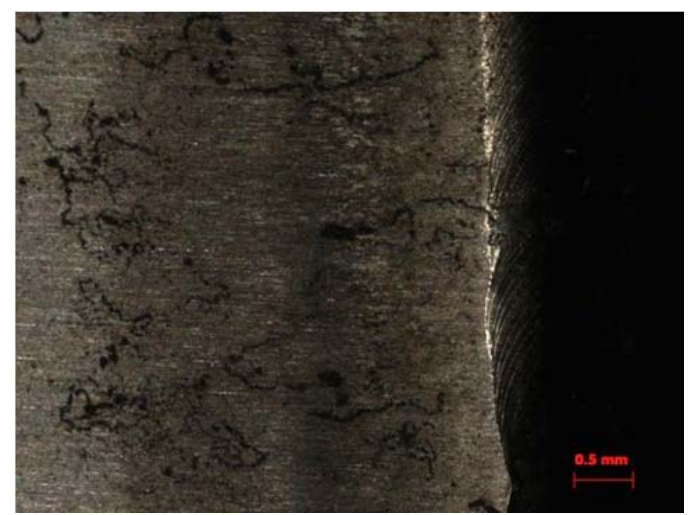

(A)

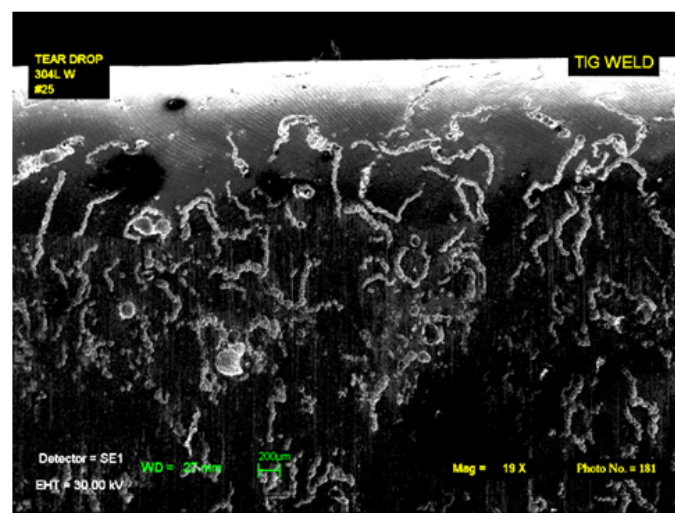

(B)

Figure 5-19 Micrographs of TIG closure weld: (A) stereo-micrograph of TD03 (25x) and (B) SEM micrograph of TD25 (19x) 


\subsection{Corrosion of 3013 Container}

Over 803013 containers have been evaluated by destructive examination (DE) as part of the 3013 surveillance program. The analysis conducted as part of DE has included some characterization of pitting in both the convenience and inner cans, although pitting in the inner can has been quite limited. Pitting morphologies are shown in Figure 5-20 for several DE containers. This pitting has occurred in surfaces with oxide/salt contact as well as vapor-exposure only.

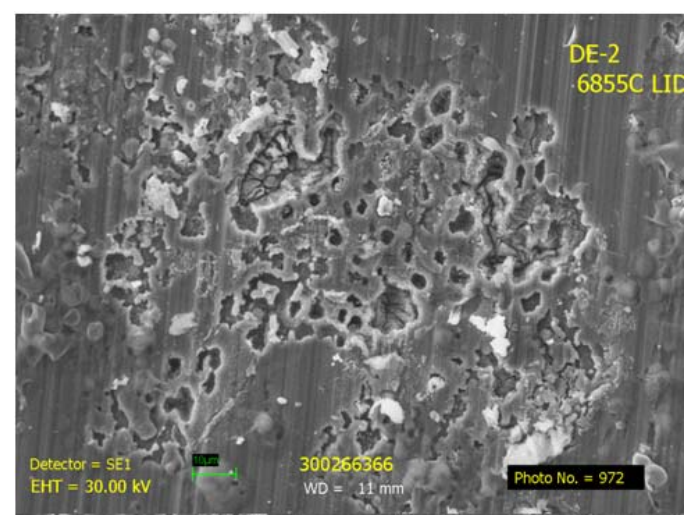

(A)

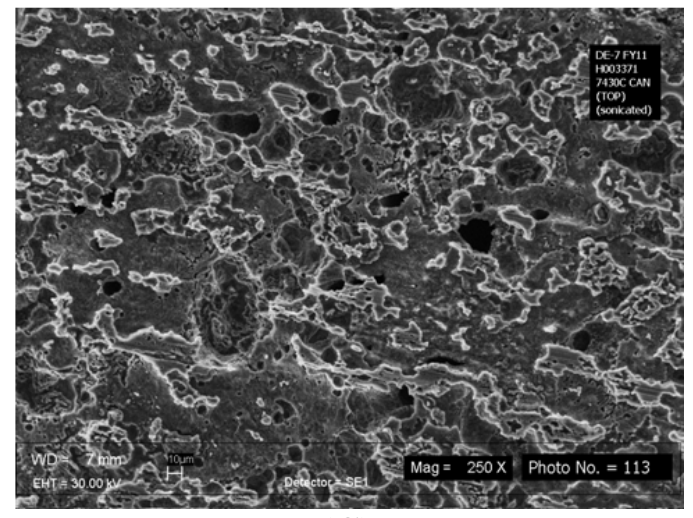

(C)

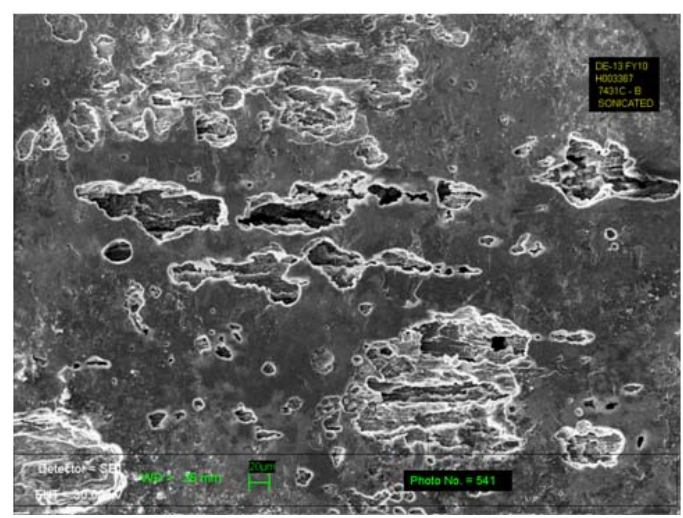

(B)

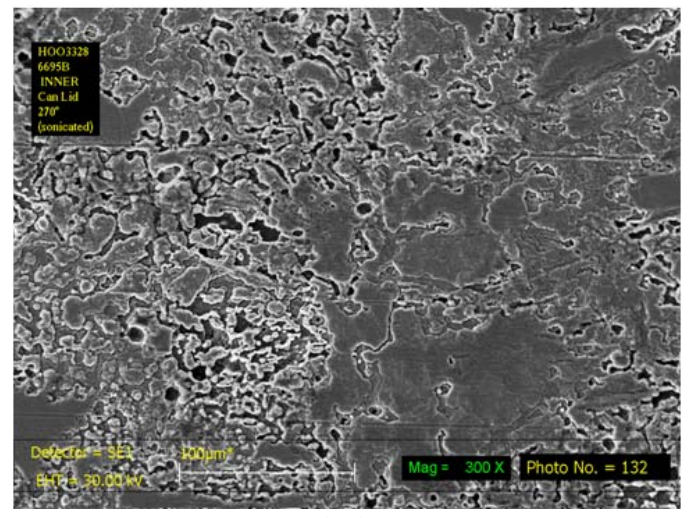

(D)

Figure 5-20 Pit morphologies observed in DE 3013 containers: (A) FY10 DE2 convenience can lid (750 x), (B) FY10 DE13 convenience can after cleaning (1075x), (C) FY11 DE7 convenience can after cleaning (250x), and (D)FY11 Hanford High Moisture Can after cleaning (300x)

The pitting shown in Figure 5-20 appears to be a general grouping of pits or localized breakdown which is similar to those observed in the teardrop coupons. The specific morphology within these areas differs and may be associated with different exposure conditions including material microstructure, chemical composition, time of exposure or storage, and moisture level.

Localized pits were also observed that show some directionality. This directionality as shown in Figure 5-20 (B) was especially noted for the convenience can of FY10 D13 (H003367). This directionality was also noted for TD05 as shown in Figure 5-2 (A). 
The circuitous nature of the degradation noted in the inner can crevice of the Hanford High Moisture container, which is vapor exposure only, does show some similarity to the circuitous pitting observed in the vapor-exposed surfaces of the teardrop coupon TIG closure weld. However, the two morphologies are not identical which may be attributed to differences in exposure conditions as listed above.

\subsection{Series 2 Test Status}

The Series 2 testing was initiated in August 2012. The moisture uptake is shown in Figure 6-1 and was approximately $0.18 \%$. The target $\mathrm{RH}$ was approximately $22 \%$, however, the initial RH of all three test containers was in the range of 35-40\%. The higher RH indicated that more water was present in the test vessels than planned. The uptake trend shows only the added moisture at the start of the test, but not moisture that may have been taken up by the oxide/salt mixture during storage after preparation but prior to the intentional addition of moisture. Although precautions were taken to keep the oxide/salt mixtures dry prior to moisture addition by the use of desiccants and double bagging, some additional moisture was likely taken up during this time.

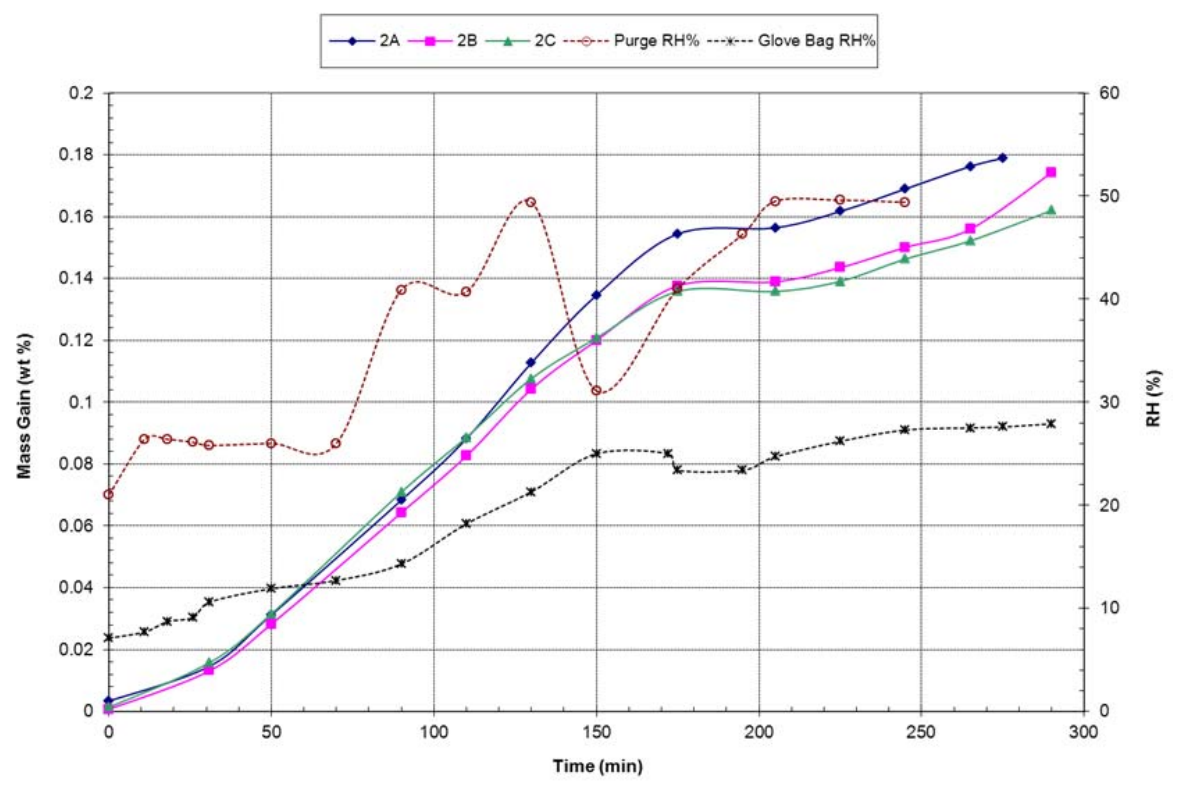

Figure 6-1 Moisture uptake during loading of test vessels for Series 2 test

The RH, pressure and temperature trends over the test duration are shown in Figure 6-2. Vessel A was opened first after 105 days since the pressure remained at atmospheric pressure after closing, indicating a leak into the test vessel. However, the RH was fairly constant over this time interval at approximately 35\%. Vessel B had a minimum around 25 days and a maximum occurring near 75 days in the pressure and RH trends, respectively. Problems with the pressure transducer led to gaps in the data. The pressure is holding at atmospheric pressure since the latest measurement at about 175 days agrees with current measurements at approximately 330 days (not shown in the figure). This change may be associated with a leak although current $\mathrm{RH}$ in the cell is below the 
glovebox humidity. The pressure trends for the three vessels differ: Vessel A was at atmospheric pressure. Vessel $\mathrm{C}$ has showed a decreasing pressure trend, which may be starting to increase. The RH trend has been continuously increasing. This trend cannot yet be explained.

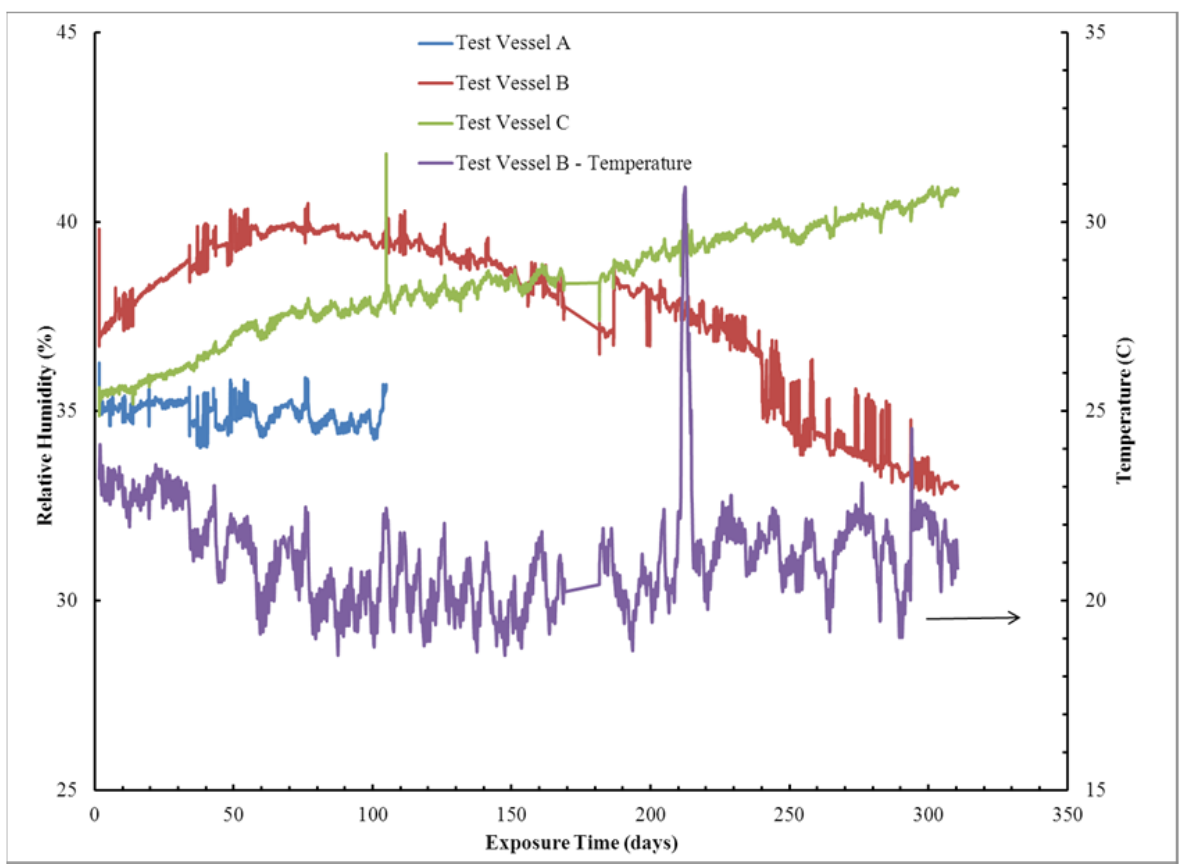

(A)

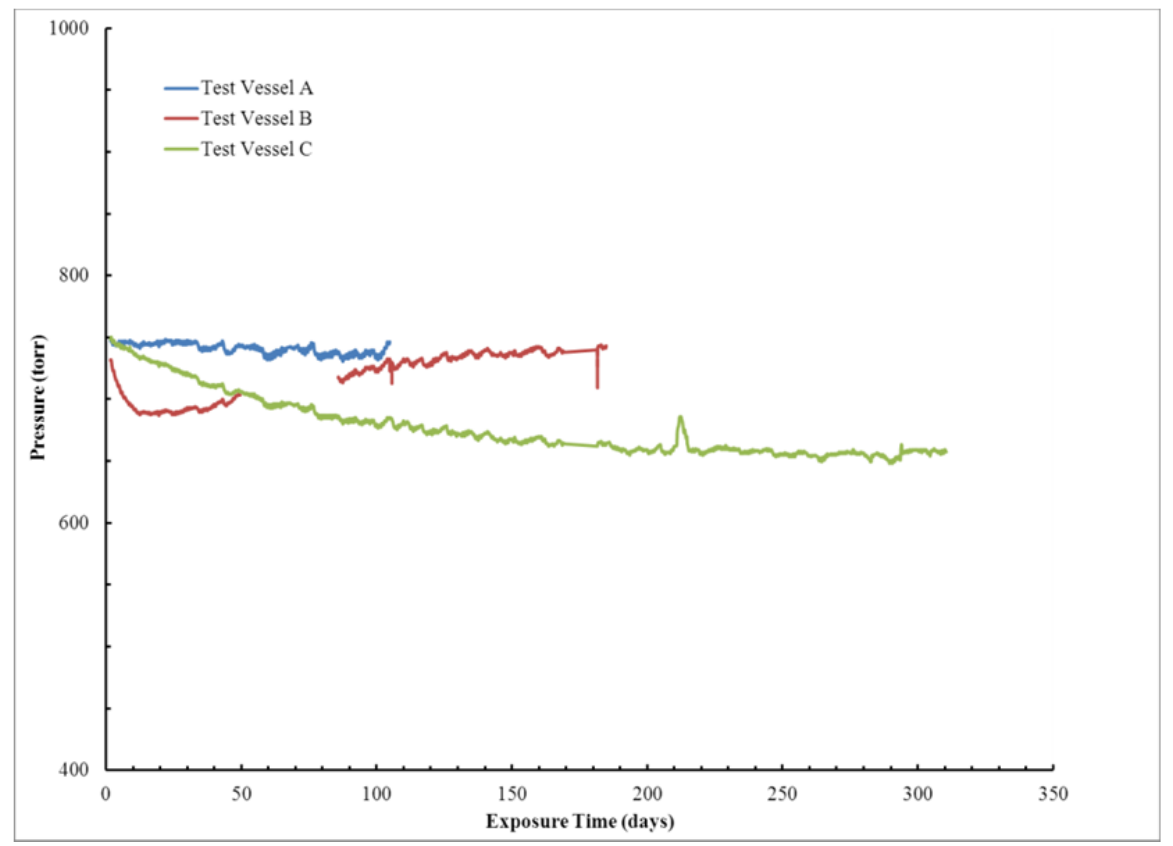

(B)

Figure 6-2 Trends in exposure conditions for Series 2 test vessels: (A) relative humidity and temperature, and (B) pressure 
The teardrop coupons from Vessel A showed a minimal amount of corrosion for both coupons. Similar to the results from Series 1 testing, the teardrop coupon (TD16) in contact with the oxide/salt mixture had more corrosion that the teardrop coupon (TD18) exposed in the vapor space. Figure 6-3 shows these coupons prior to cleaning. TD16 had spotty corrosion products on the surface that appeared to be pit like on both the interior and exterior surface of the teardrop. TD18 had some surface oxidation as shown by the circular spot in Figure 6-3 (C). These coupons will be examined further at the completion of the Series 2 test. The next test vessel will be opened at approximately one year from the test initiation.

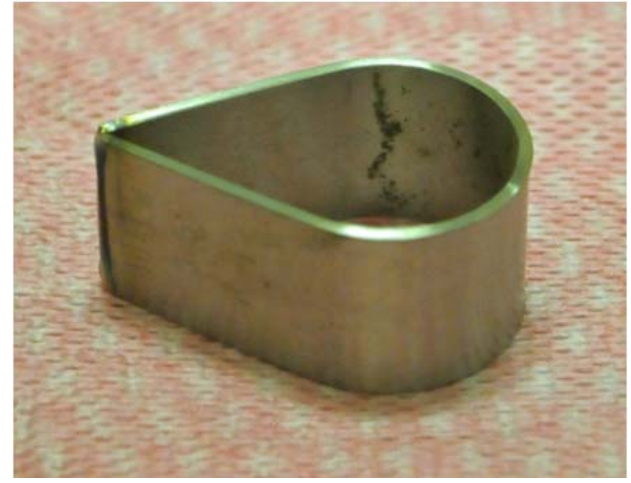

(A)

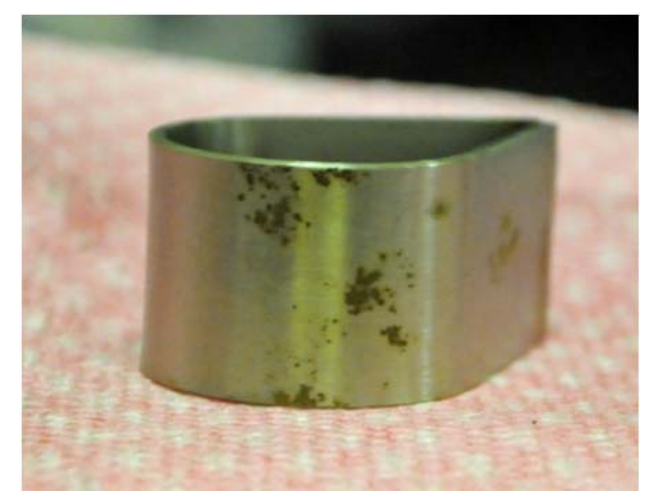

(B)

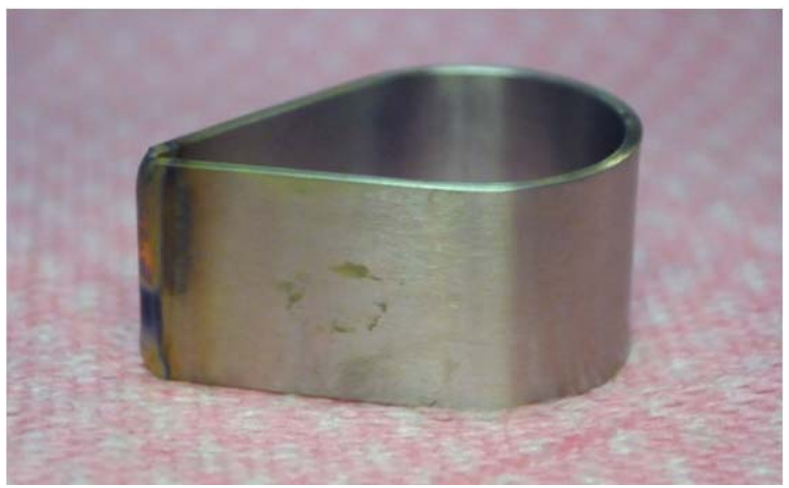

(C)

Figure 6-3 Photographs of Vessel A coupons after 105-day exposure in Series 2 testing: (A and B) coupon TD16, oxide/salt contact, as-is condition; and (C) coupon TD18, vapor exposure, as-is condition

\subsection{Conclusion}

The Phase II, Series 1 testing has shown that SCC and pitting will occur in 304L stainless steel at room temperature (19 to $24{ }^{\circ} \mathrm{C}$ ) with direct exposure to a moist $(\sim 0.5 \mathrm{wt} \%)$ plutonium oxide and chloride salt mixture stored under humid conditions (50-55\% relative humidity). These results are similar to those observed during Phase I testing of the small-scale shelf-life testing. Pit and crack initiation and propagation were observed to progress with increased time at the exposure conditions. Cracking was generally found 
to be associated with pits or localized areas of corrosion, although sites of crack initiation could not be always identified. The smallest measured pit associated with a crack was less than $50 \mu \mathrm{m}$. On the vapor-exposed surfaces, the pits exhibited a "pearl necklace" morphology which is a linking of pits along a linear trajectory. The teardrop coupon TIG closure welds with a heat tint on the surface always had pitting or pit-like features in a similar "pearl necklace” morphology. The pitting observed in the teardrop coupons showed some similarity to that observed during DE of 3013 containers.

\subsection{References}

1. "Stabilization, Packaging, And Storage of Plutonium-Bearing Materials", DOESTD-3013-2004, U. S. Dept. of Energy, 2012

2. K. A. Dunn, R. R. Livingston and P. E. Zapp, “Task Technical and Quality Assurance Plan: Corrsion Tests of 304L and 316L Stainless Steels for the 3013 Container,” WSRC-TR-2006-00293, September, 2006

3. R. S. Lillard, D. K. Veirs, J. M. Berg, L. A. Worl, J. M. Duffey, K. A. Dunn, R. R. Livingston, P. E. Zapp, and J. W. McClard, “Test Plan for Determining the Susceptibility of 3013 Containers to Stress Corrosion Cracking,” LA-UR-09-02953, June 2009

4. P. E. Zapp and J. M. Duffey, "Status Report for the SRNL 3013 Corrosion Tests," SRNS-STI-2008-00093, October 2008

5. D. K. Veirs, L.A. Worl, D. M. Harradine, M.A. Martinez, M. A., R.S. Lillard, D.S. Schwartz, C.V. Puglisi, D.D. Padilla, A. Carrillo, R.E. McInroy, and A.R. Montoya, "Gas Generation and Corrosion in Salt-Containing Impure Plutonium Oxide Materials: Initial Results for ARF-102-85-223,” LA-UR-04-1788, June, 2004

6. P. E. Zapp and R. R. Livingston, "Corrosion Tests of 304L and 316L Stainless Steels for the 3013 Container,” WSRC-TR-2005-00191, September 2005

7. L. A. Worl et al, "Impact of Stress Corrosion Cracking Observed in Shelf-life Specimens for 3013 Containers,” LA-UR-08-05959, September, 2008

8. R. S. Lillard et al, “2005 Update to: A Comprehensive, Site-Wide Program for Addressing Potential 3013 Corrosion Issues," Los Alamos National Laboratory Report LA-UR-05-7652.

9. J. I. Mickalonis and J. E. Duffey, "Relative Humidity Tests in Support of the 3013 Storage and Surveillance Program,” SRNL-STI-2010-00409, August 2011

10. P. S. Lam, P. E. Zapp, and J. M. Duffey, "Stress Corrosion Cracking in Tear Drop Specimens,” Proceedings of the ASME 2009 Pressure Vessels and Piping Division Conference, July 2009 
11. A. H. Tuthill and R. E. Avery, "Heat Tint on Stainless Steels Can Cause Corrosion Problems,” Materials Performance, Vol (2), 1999

12. D. K. Veirs, "Gas generation from water adsorbed onto pure plutonium dioxide powder," Proceedings of the Materials Research Society Symposium 893, Actinides 2005 - Basic Science, Applications and Technology, Paper No. 0893-JJ07-03.1

13. Leak Test Reports, Job Number SRNL-HPL-2010-4354, 2010 